\title{
Serotonergic Modulation of Nigrostriatal and Mesolimbic Dopamine and Motor/Exploratory Behaviors in the Rat
}

\author{
Susanne Nikolaus ${ }^{1 *}$, Hans-Jörg Wittsack ${ }^{2}$, Christina Antke ${ }^{1}$, Markus Beu ${ }^{1}$, \\ Hubertus Hautzel ${ }^{3}$, Cvetana Decheva ${ }^{4}$, Eduards Mamlins ${ }^{1}$, Yuriko Mori ${ }^{1}$, \\ Joseph P. Huston ${ }^{4}$, Gerald Antoch ${ }^{2}$ and Hans-Wilhelm Müller ${ }^{1}$ \\ ${ }^{1}$ Clinic of Nuclear Medicine, University Hospital Düsseldorf, Düsseldorf, Germany, ${ }^{2}$ Department of Diagnostic and \\ Interventional Radiology, University Hospital Düsseldorf, Düsseldorf, Germany, ${ }^{3}$ Clinic for Nuclear Medicine, University \\ Hospital Essen, Essen, Germany, ${ }^{4}$ Center for Behavioural Neuroscience, Institute of Experimental Psychology, \\ Heinrich-Heine University, Düsseldorf, Germany
}

\section{OPEN ACCESS}

Edited by:

Tod Edward Kippin

University of California, Santa Barbara,

United States

Reviewed by:

Marcelo Febo,

University of Florida, United States

Arnab Mukherjee,

University of California, Santa Barbara,

United States

Janet L. Neisewander,

Arizona State University, United States

*Correspondence:

Susanne Nikolaus

susanne.nikolaus@uni-duesseldorf.de

Specialty section: This article was submitted to

Neuropharmacology,

a section of the journal

Frontiers in Neuroscience

Received: 23 March 2021

Accepted: 12 July 2021

Published: 12 August 2021

Citation:

Nikolaus S, Wittsack H-J, Antke C, Beu M, Hautzel H, Decheva C,

Mamlins E, Mori Y, Huston JP, Antoch $G$ and Müller H-W (2021)

Serotonergic Modulation of

Nigrostriatal and Mesolimbic

Dopamine and Motor/Exploratory Behaviors in the Rat.

Front. Neurosci. 15:682398.

doi: 10.3389/fnins.2021.682398
Purpose: The 5- $\mathrm{HT}_{2 \mathrm{~A}}$ receptor $(\mathrm{R})$ is known to modulate dopamine (DA) release in the mammalian brain. Altanserin (ALT) and 2,5-dimethoxy-4-iodoamphetamine (DOI) act as $5-\mathrm{HT}_{2 \mathrm{~A}} \mathrm{R}$ antagonist and agonist, respectively. In the present study, we assessed the effects of ALT and DOI on motor and exploratory behaviors and on $D_{2 / 3} R$ binding in the rat brain with in vivo imaging methods.

Methods: $D_{2 / 3} R$ binding was determined after systemic application of ALT (10 mg/kg) or DOI $(0.5 \mathrm{mg} / \mathrm{kg})$ and the respective vehicles [dimethyl sulfoxide (DMSO) and 0.9\% saline (SAL)] with [ ${ }^{123}$ I]IBZM as a single-photon emission computed tomography (SPECT) radioligand. Anatomical information for the delineation of the target regions was obtained with dedicated small animal MRI. Immediately after $5-\mathrm{HT}_{2 \mathrm{~A}} \mathrm{R}$ antagonistic or agonistic treatment, motor/exploratory behaviors were assessed for 45 (ALT) or 30 min (DOI) in an open field. Additional rats underwent behavioral measurements after injection of DMSO or SAL.

Results: ALT increased $D_{2 / 3} R$ binding in the ventral hippocampus relative to vehicle, while DOI augmented $\mathrm{D}_{2 / 3} \mathrm{R}$ binding in caudate putamen, frontal cortex, motor cortex, and ventral hippocampus. The $5-\mathrm{HT}_{2 \mathrm{~A}} \mathrm{R}$ agonist as well as antagonist decreased parameters of motor activity and active exploration. However, ALT, in contrast to DOI, decreased explorative head-shoulder motility and increased sitting.

Conclusions: The regional increases of $\mathrm{D}_{2 / 3} \mathrm{R}$ binding after ALT and DOI (90 and $75 \mathrm{~min}$ post-challenge) may be conceived to reflect decreases of synaptic DA. The reductions of motor/exploratory activities ( $\min 1-45$ and min 1-30 after challenge with ALT and DOI, respectively) contrast the regional reductions of $D_{2 / 3} R$ binding, as they indicate elevated DA levels at the time of behavioral measurements. It may be concluded that ALT and DOI modulate DA in the individual regions of the nigrostriatal and mesolimbocortical pathways differentially and in a time-dependent fashion.

Keywords: $\mathrm{D}_{2 / 3}$ receptor, $\left.{ }^{123}{ }^{12}\right] \mathrm{IBZM}, 5-\mathrm{HT}_{2 \mathrm{~A}}$ receptor, altanserin, 2,5-dimethoxy-4-iodoamphetamine 


\section{INTRODUCTION}

Serotonin(5-HT)ergic innervation of the mammalian brain originates in the rostral and caudal raphe nuclei of the brainstem: the efferent projections of the rostal group ascend to the nuclei of the basal ganglia including the substantia nigra ( $\mathrm{SN}$; Wirtshafter et al., 1987), caudate putamen (CP; Steinbusch et al., 1980), globus pallidus (Eid and Parent, 2016), and subthalamic nucleus (Carpenter et al., 1981). Further projections rise to the ventral tegmental area (VTA; Oades and Halliday, 1987), nucleus accumbens (NAC; Ma and Han, 1992), thalamus (THAL; Moore et al., 1978), hypothalamus (Larsen et al., 1996), neocortex (Kievit and Kuypers, 1975), and limbic regions including the amygdala and hippocampus (HIPP; Köhler and Steinbusch, 1982), while others descend to the superior colliculus (Villar et al., 1988); the pedunculopontine tegmental, trigeminal, and cochlear brainstem nuclei (Li et al., 1993; Thompson et al., 1995; Steininger et al., 1997); the cerebellum (Torigoe et al., 1986) and the spinal cord (Kazakov et al., 1993). The caudal raphe nuclei project to the visceral and somatic motor nuclei, to the lateral reticular formation, and also to the spinal cord (Li et al., 1993; Manaker and Fogarty, 1995; Ribeiro-do-Valle, 1997).

In addition to 5-HT, the raphe nuclei contain a variety of other neurotransmitters including glutamate (GLU; Kaneko et al., 1990), $\gamma$-amino butyric acid (GABA; Belin et al., 1979), and dopamine (DA; Ochi and Shimizu, 1978). Thereby, the dorsal raphe nucleus sends DAergic efferents to NAC, CP, prefrontal cortex (PFC), and septum (Stratford and Wirtshafter, 1990). Neurochemical studies indicate that 5 -HT modulates DAergic activity and DA release (for review, see, e.g., Alex and Pehek, 2007). Disturbances of both 5-HTergic and DAergic function have been implied in numerous psychiatric and neurological conditions (for review, see, e.g., Nikolaus et al., 2009a,b). Both neurotransmitter systems are relevant for a variety of functions including motor control, learning, and reward-seeking behavior (for review, see, e.g., Arias-Carrión and Poppel, 2007; Fischer and Ullsperger, 2017; Kawashima, 2018).

Altanserin (ALT) is a potent antagonist of $5-\mathrm{HT}_{2 \mathrm{~A}}$ receptors [R; dissociation constant $\left(\mathrm{K}_{\mathrm{d}}\right)=0.3 \mathrm{nM}$; Kristiansen et al., 2005] with $>100$-fold selectivity over $\mathrm{D}_{2 / 3} \mathrm{R}, 5-\mathrm{HT}_{1 \mathrm{~A}} \mathrm{R}, 5-\mathrm{HT}_{6} \mathrm{R}$, and 5-HT 7 R (Leysen, 1989; Tan et al., 1999). 2,5-Dimethoxy4-iodoamphetamine (DOI) has $5-\mathrm{HT}_{2 \mathrm{~A}} \mathrm{R}$ agonistic properties $\left(\mathrm{K}_{\mathrm{d}}=4 \mathrm{nM}\right.$, Appel et al., 1990) with $\sim 10$-fold selectivity over 5- $\mathrm{HT}_{2 \mathrm{C}} \mathrm{R}$ (Canal et al., 2013).

In the only available behavioral study in rats, ALT $[2.5 \mathrm{mg} / \mathrm{kg}$ subcutaneously (s.c.)] was observed to reduce locomotion (Kennett, 1992), while, in a microdialysis experiment (also in rats), intraperitoneal (i.p.) application of $20 \mathrm{mg} / \mathrm{kg}$ elicited an increase of striatal DA levels (Dewey et al., 1995).

In rats, DOI (0.25 mg/kg s.c., Krebs-Thomson et al., 1998; 0.3 and $1 \mathrm{mg} / \mathrm{kg}$, s.c., Zaniewska et al., 2009; 0.25-4 mg/kg s.c., Hillegaart et al., 1996) reduced locomotion (Krebs-Thomson et al., 1998; Zaniewska et al., 2009) and rearing (Hillegaart et al., 1996; Krebs-Thomson et al., 1998). Decreases of rearing behavior were also observed by Hawkins et al. (2002) after intracerebroventricular (i.c.v.) and s.c. administration of 20-200 $\mu \mathrm{g}$ and $0.1-1 \mathrm{mg} / \mathrm{kg}$, respectively. However, they found no effect on motor activity.

Systemic DOI (2 mg/kg i.p., Gudelsky et al., 1994; $2.5 \mathrm{mg} / \mathrm{kg}$ i.p. Ichikawa and Meltzer, 1995) exerted no effect on DA efflux in NAC (Ichikawa and Meltzer, 1995) and CP (Gudelsky et al., 1994; Ichikawa and Meltzer, 1995), whereas infusion into NAC (10-300 $\mu \mathrm{M}$; Yan et al., 2000), CP (1 $\mu \mathrm{M}$; Lucas and Spampinato, 2000), and PFC (300 $\mu \mathrm{M}$; Bortolozzi et al., 2005) increased DA levels in these regions as well as in the VTA (Bortolozzi et al., 2005). Moreover, application of 0.1-10 mg/kg s.c. elevated DA release in the frontal cortex (FC; Gobert and Millan, 1999). These findings are in contrast to the report of $\mathrm{Ng}$ et al. (1999), who observed a decrease of DA efflux in the CP upon infusion of 10 and $20 \mu \mathrm{M}$ of DOI into this region.

So far, little is known about the behavioral and neurochemical effects of ALT in rats. Moreover, findings on DOI have been controversial with respect to both neurochemistry and behavior. Also, in vivo imaging evidence is scarce: as of yet, one in vivo imaging study of striatal $\mathrm{D}_{2 / 3} \mathrm{R}$ binding has been conducted on baboons upon pretreatment with ALT $[1 \mathrm{mg} / \mathrm{kg}$ intravenously (i.v.)], showing a reduction of $\left[{ }^{11} \mathrm{C}\right]$ raclopride binding in the $\mathrm{CP}$ indicative of an elevation of extracellular DA (Dewey et al., 1995). After treatment with DOI, so far, no in vivo imaging studies of $\mathrm{D}_{2 / 3} \mathrm{R}$ binding have been conducted on humans, non-human primates, or rats.

In the present study, we investigated the effects of systemic ALT $(10 \mathrm{mg} / \mathrm{kg}$ i.p.) or DOI $(0.5 \mathrm{mg} / \mathrm{kg}$ i.p.) on both motor/exploratory behaviors and $\mathrm{D}_{2 / 3} \mathrm{R}$ binding in regions of the rat nigrostriatal and mesolimbic systems, which are involved in motor as well as cognitive and emotional functioning [NAC, CP, THAL, SN/VTA, FC, motor cortex (MC), parietal cortex (PC), dorsal HIPP (dHIPP), ventral HIPP (vHIPP)], using small animal single-photon emission computed tomography (SPECT). Autoradiography studies have confirmed the presence of $\mathrm{D}_{2 / 3} \mathrm{R}$ binding sites for all of these areas, including those of the HIPP and neocortex (Bouthenet et al., 1987; Seeman and Grigoriadis, 1987; Morelli et al., 1990). Anatomical information for the delineation of the target regions was obtained with dedicated small animal MRI.

\section{MATERIALS AND METHODS}

\section{Animals}

Studies were conducted on a total of 71 male Wistar rats (ZETT, Heinrich-Heine University, Düsseldorf, Germany), weighing 437 $\pm 51 \mathrm{~g}$ [mean \pm standard deviation (SD); age, 3-4 months]. Rats were kept in standard Makrolon cages $(590 \times 380$ $\times 200 \mathrm{~mm}$; three animals per cage) in a climate cabinet (Scantainer, Scanbur BK, Karlslunde, Denmark; temperature, $20-22^{\circ} \mathrm{C}$; air humidity, 60-70\%) with an artificial lightdark cycle (lights on at 6:00 a.m., lights off at 6:00 p.m.). Temperature and air humidity were checked on a daily basis. Food and water were freely available. The protocol was approved by the regional authority (Landesamt für Natur, Umwelt und Verbraucherschutz, Nordrhein-Westfalen, Recklinghausen, Germany) and carried out in accordance with the European 


\section{A}

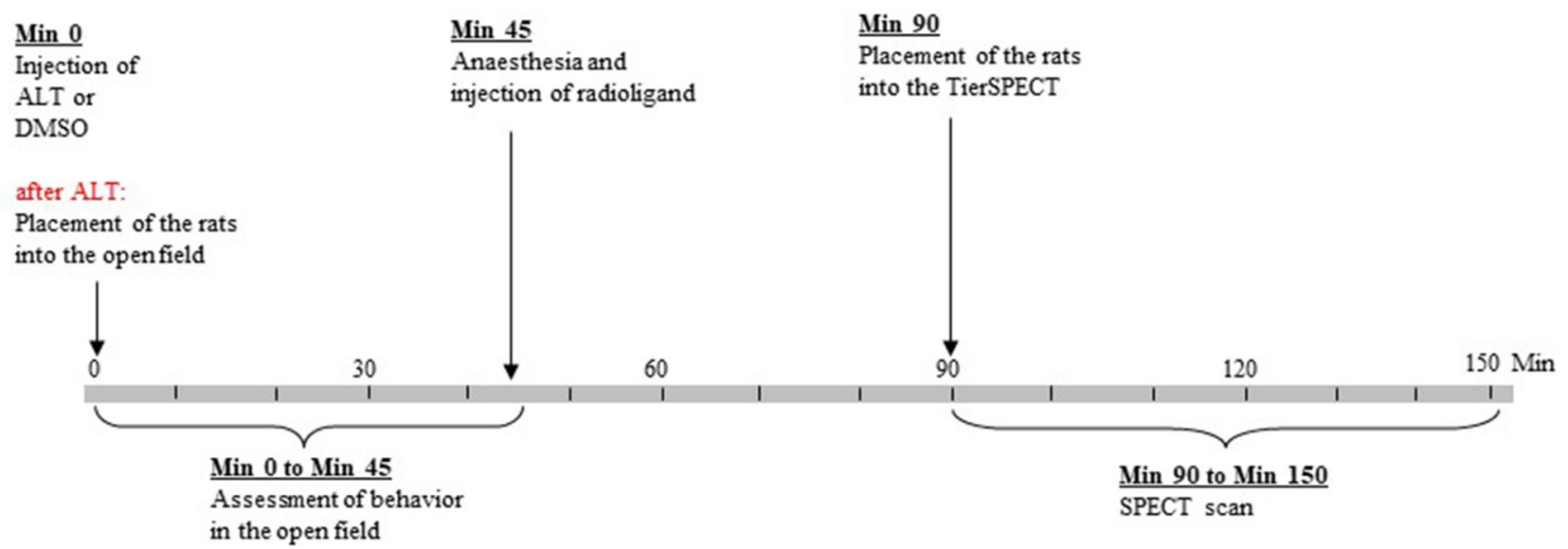

B

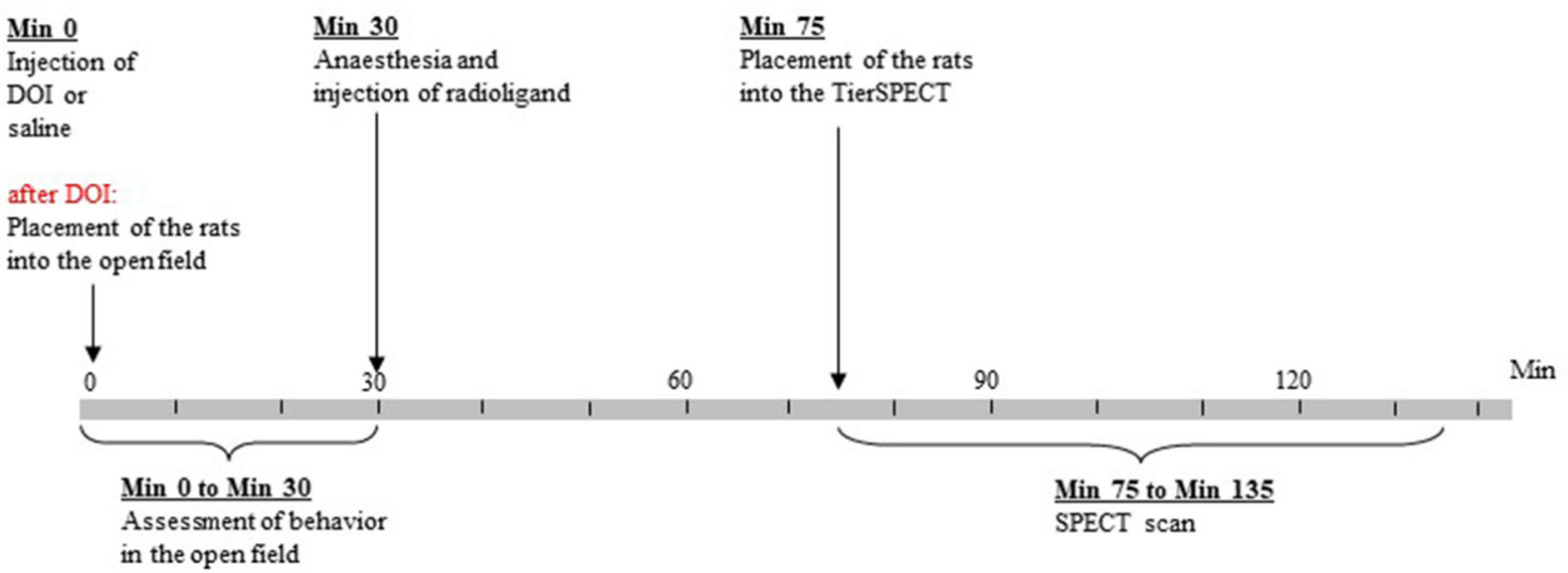

FIGURE 1 | Time lines of experimental procedures. (A) Treatment with altanserin (ALT) and dimethyl sulfoxide (DMSO). (B) Treatment with 2,5-dimethoxy-4iodoamphetamine (DOI) and saline.

Communities Council Directive (86/609/EEC) and the German Law on the Protection of Animals.

\section{Study Design}

Forty rats underwent (1) morphological MRI, (2) $\mathrm{D}_{2 / 3} \mathrm{R}$ imaging after 5-HTergic challenge (ALT or DOI), and (3) $\mathrm{D}_{2 / 3} \mathrm{R}$ imaging after administration of the respective vehicle [dimethyl sulfoxide (DMSO) or $0.9 \%$ physiological saline (SAL)]. Immediately after 5-HTergic challenges, rats underwent behavioral testing in an open field (Figure 1). The two SPECT measurements (including behavioral assessment after 5-HTergic challenges) were performed 7 days apart and in a randomized order. Due to cardiac arrest after the administration of the anesthetics, two rats merely underwent behavioral measurements (ALT, $n=1$; DOI, $n$ $=1$ ) without subsequent $\mathrm{D}_{2 / 3} \mathrm{R}$ imaging.

In order to obtain comparative behavioral data, 31 further rats of the same strain, age, and weight merely underwent testing in the open field after precedent treatment with DMSO $(n=15)$ and $\operatorname{SAL}(n=16)$.

\section{MRI Studies}

After administration of ketamine hydrochloride (Ketavet ${ }^{\circledR}$, Pharmacia GmbH, Erlangen, Germany; dose, $50 \mathrm{mg} / \mathrm{kg}$ i.p.; concentration, $100 \mathrm{mg} / \mathrm{ml}$ ) and xylazine hydrochloride (Rompun ${ }^{\circledR}$, Bayer, Leverkusen, Germany; dose, $2.5 \mathrm{mg} / \mathrm{kg}$ i.p.; concentration, $20 \mathrm{mg} / \mathrm{ml}$ ), morphological imaging was performed with a dedicated small animal MRI (MRS3000 Preclinical MRI, 3.0 T, MR Solutions, Guildford, UK; coil diameter, $54 \mathrm{~mm}$; field of view, $64 \times 64 \times 44 \mathrm{~mm}$; spatial resolution, $0.25 \times 0.25 \times 0.69)$. High-resolution images were obtained by performing $3 \mathrm{D}$ fast low-angle shot (FLASH) sequences (image matrix, $192 \times 192 \times 96$; echo time, $4.87 \mathrm{~ms}$; repetition time, $30 \mathrm{~ms}$; excitation flip angle, $30^{\circ}$; total acquisition time, $9.22 \mathrm{~min}$; Haase et al., 1986). 


\section{Drug Treatment}

Rats received either ALT (Sigma-Aldrich, Taufkirchen, Germany; molecular weight, $411.49 \mathrm{~g} / \mathrm{mol}$; dose, $10 \mathrm{mg} / \mathrm{kg}$ i.p.; injection volume, $0.5 \mathrm{ml} / \mathrm{kg}$; concentration, $20 \mathrm{mg} / \mathrm{ml} ; n=21$ ), $( \pm)$ DOI hydrochloride (Sigma-Aldrich, Taufkirchen, Germany; molecular weight, $357.62 \mathrm{~g} / \mathrm{mol}$; dose, $0.5 \mathrm{mg} / \mathrm{kg}$ i.p.; injection volume, $1 \mathrm{ml} / \mathrm{kg}$; concentration, $0.5 \mathrm{mg} / \mathrm{ml} ; n=19$ ) or the vehicles DMSO (for ALT; 100\%; Sigma-Aldrich, Taufkirchen, Germany; molecular weight, $78.13 \mathrm{~g} / \mathrm{mol}$; dose, $0.5 \mathrm{ml} / \mathrm{kg}$ i.p.) and isotonic SAL (for DOI; B. Braun Melsungen AG, Melsungen, Germany; molecular weight: $58.5 \mathrm{~g} / \mathrm{mol}$; dose, $1 \mathrm{ml} / \mathrm{kg}$ i.p.).

In the available studies, ALT was behaviorally and pharmacologically active after systemic doses of $2.5 \mathrm{mg} / \mathrm{kg}$ (Kennett, 1992) and $20 \mathrm{mg} / \mathrm{kg}$ (Dewey et al., 1995), respectively. DOI proved behaviorally active after systemically applied doses between 0.05 and $4 \mathrm{mg} / \mathrm{kg}$ (Hillegaart et al., 1996), while neurochemical effects were observed between 0.1 and $10 \mathrm{mg} / \mathrm{kg}$ (Gobert and Millan, 1999). Based on these findings, we chose intermediate doses of $10 \mathrm{mg} / \mathrm{kg}$ of ALT and $0.5 \mathrm{mg} / \mathrm{kg}$ of DOI, respectively.

\section{Single-Photon Emission Computed Tomography Studies}

The employed small animal tomograph (“TierSPECT”; Central Institute for Electronics, Research Center Jülich, Jülich, Germany) was described in detail elsewhere (Schramm et al., 2000). Briefly, the detector consists of a $\mathrm{NaI}(\mathrm{Tl})$ disk (thickness, $3 \mathrm{~mm}$ ) coupled to a position-sensitive photomultiplier (Hamamatsu R3292) and mounted on a rotating gantry ffield of view, $82 \mathrm{~mm}$; tomographic resolution [full width at half maximum (FWHM)] for ${ }^{123} \mathrm{I}, 3.4 \mathrm{~mm}$; sensitivity for ${ }^{123} \mathrm{I}$, $16 \mathrm{cps} / \mathrm{MBq}\}$. In the present study, a low-energy ultra-highresolution parallel-hole collimator (LEUHR, $37 \times 1 \times 0.2 \mathrm{~mm}^{3}$ ) was employed. Imaging data were recorded in a step-and-shoot mode over a circular orbit (radius of rotation, $65 \mathrm{~mm}$ ) in angular steps of $6^{\circ}$ (60 projections, $60 \mathrm{~s} /$ projection). The $15 \%$ energy window was centered on the $159-\mathrm{keV}$ gamma photopeak of ${ }^{123} \mathrm{I}$. Data were acquired in a $128 \times 128$ matrix with a pixel width and a slice thickness of $\approx 0.664 \mathrm{~mm}$, respectively. Reconstruction was performed with an iterative ordered-subset-expectationmaximization algorithm (three iterations, four subsets/iteration). No post-filtering procedure was applied. An attenuation correction was implemented assuming a uniformly attenuating medium (linear attenuation coefficient, $0.10 \mathrm{~cm}^{-1}$ ).

Upon anesthesia with ketamine hydrochloride (dose, $100 \mathrm{mg} / \mathrm{kg}$ i.p.; concentration, $100 \mathrm{mg} / \mathrm{ml}$ ) and xylazine hydrochloride (dose, $5 \mathrm{mg} / \mathrm{kg}$ i.p.; concentration, $20 \mathrm{mg} / \mathrm{ml}$ ), $\left.{ }^{123} \mathrm{I}\right] \mathrm{S}$-3-iodo- $N$-(1-ethyl-2-pyrrolidinyl)methyl-2-hydroxy-

6-methoxy benzamide ([ $\left.{ }^{123} \mathrm{I}\right] \mathrm{IBZM}$; GE Healthcare, Munich, Germany; activity, $29.9 \pm 3.4 \mathrm{MBq}$; concentration, $3.4 \times 10^{-9}$ $\mathrm{g} / \mathrm{ml}$; specific activity, $>74 \mathrm{TBq} / \mathrm{mmol}$ at reference time) was injected into the tail vein. With an applied mean radioactivity of $30 \mathrm{MBq}$, a mean animal weight of $437 \mathrm{~g}$, a specific activity of $>74$ $\mathrm{TBq} / \mathrm{mmol}$, and an affinity of $\sim 0.3 \mathrm{nM}$ (Verhoeff et al., 1991), according to Hume et al. (1998), a $\mathrm{D}_{2 / 3} \mathrm{R}$ occupancy in the range of $2 \%$ may be expected.
In previous studies conducted with the "TierSPECT," we have demonstrated the displaceability of this radioligand from the $\mathrm{D}_{2 / 3} \mathrm{R}$ binding site by endogenous DA (e.g., Nikolaus et al., 2016). In both humans (Verhoeff et al., 1991) and rodents (Verhoeff et al., 1991; Jongen et al., 2008), under various anesthetics including ketamine (Jongen et al., 2008).

Specific binding of $\left[{ }^{123} \mathrm{I}\right] \mathrm{IBZM}$ in the striatum reaches its maximum at $40 \mathrm{~min}$ post-injection and remains stable for up to $2 \mathrm{~h}$. This coincides with the time of maximum DA concentrations after administration of ALT (40-60 min postchallenge; Dewey et al., 1995) and DOI (20-60 min postchallenge; Gobert and Millan, 1999). In order to account for these time courses, data acquisition was started $45 \mathrm{~min}$ after radioligand administration (ALT and DMSO, $90 \mathrm{~min}$ posttreatment; DOI and SAL, $75 \mathrm{~min}$ post-treatment) and ended 60 min later (ALT and DMSO, 150 min post-treatment; DOI and SAL, $135 \mathrm{~min}$ post-treatment). Animals were kept under anesthesia from $5 \mathrm{~min}$ before radioligand application until the end of data acquisition, receiving total quantities of up to $60 \mathrm{mg}$ of ketamine hydrochloride and $12 \mathrm{mg}$ of xylazine hydrochloride.

\section{Behavioral Studies}

Immediately after administration of ALT, DOI, DMSO, or SAL, motor and exploratory behaviors were assessed in an open field (Phenotyper ${ }^{\circledR}$, Noldus Information Technology, Wageningen, The Netherlands; dimensions, $45 \times 45 \times 56 \mathrm{~cm}$; illumination, $19 \mathrm{~lx}$ ) with EthoVision XT (Noldus Information Technology, Wageningen, The Netherlands).

In previous microdialysis studies, DA peaks were reached at about $40 \mathrm{~min}$ (ALT; Dewey et al., 1995) and $20 \mathrm{~min}$ (DOI; Gobert and Millan, 1999) post-injection. Hence, for a total of 45 (ALT and DMSO) or $30 \mathrm{~min}$ (DOI and SAL; Figure 1), durations (s) and frequencies (counts) of the following behaviors were rated in blocks of $5 \mathrm{~min}$ by one of the investigators (SN): (a) ambulation (as measure of motor activity); (b) sitting (as measure of "passive immobility"; Müller et al., 2004); (c) rearing (as measure of active exploration); and (d) explorative movements of head, neck, and shoulders, while the animal was sitting. Thereby, head and shoulder movements related to grooming behavior were explicitly excluded. Furthermore, based on the movement of the animal's center point, EthoVision XT automatically determined the distance in $\mathrm{cm}$ covered by the rat. Since the center point of a rat shifts not only on account of horizontal movements but also on account of vertical and diagonal movements, as they occur in rearing behavior and head-shoulder motility, the resulting distances can be considered as a measure of overall motor activity. Behavioral studies were conducted between 9:00 a.m. and 5:00 p.m. Following the behavioral tests, rats were anesthetized as described above and injected [ $\left.{ }^{123} \mathrm{I}\right] \mathrm{IBZM}$.

\section{Evaluation of Single-Photon Emission Computed Tomography Imaging Studies}

$\mathrm{D}_{2 / 3} \mathrm{R}$ imaging data were analyzed with PMOD (version 3.5, PMOD Technologies Ltd., Zürich, Switzerland). For each rat, SPECT and MR images were coregistered. Then, the MRI was coregistered with the Paxinos standard rat brain MRI (Schiffer et al., 2006) provided by PMOD. The necessary mathematical 


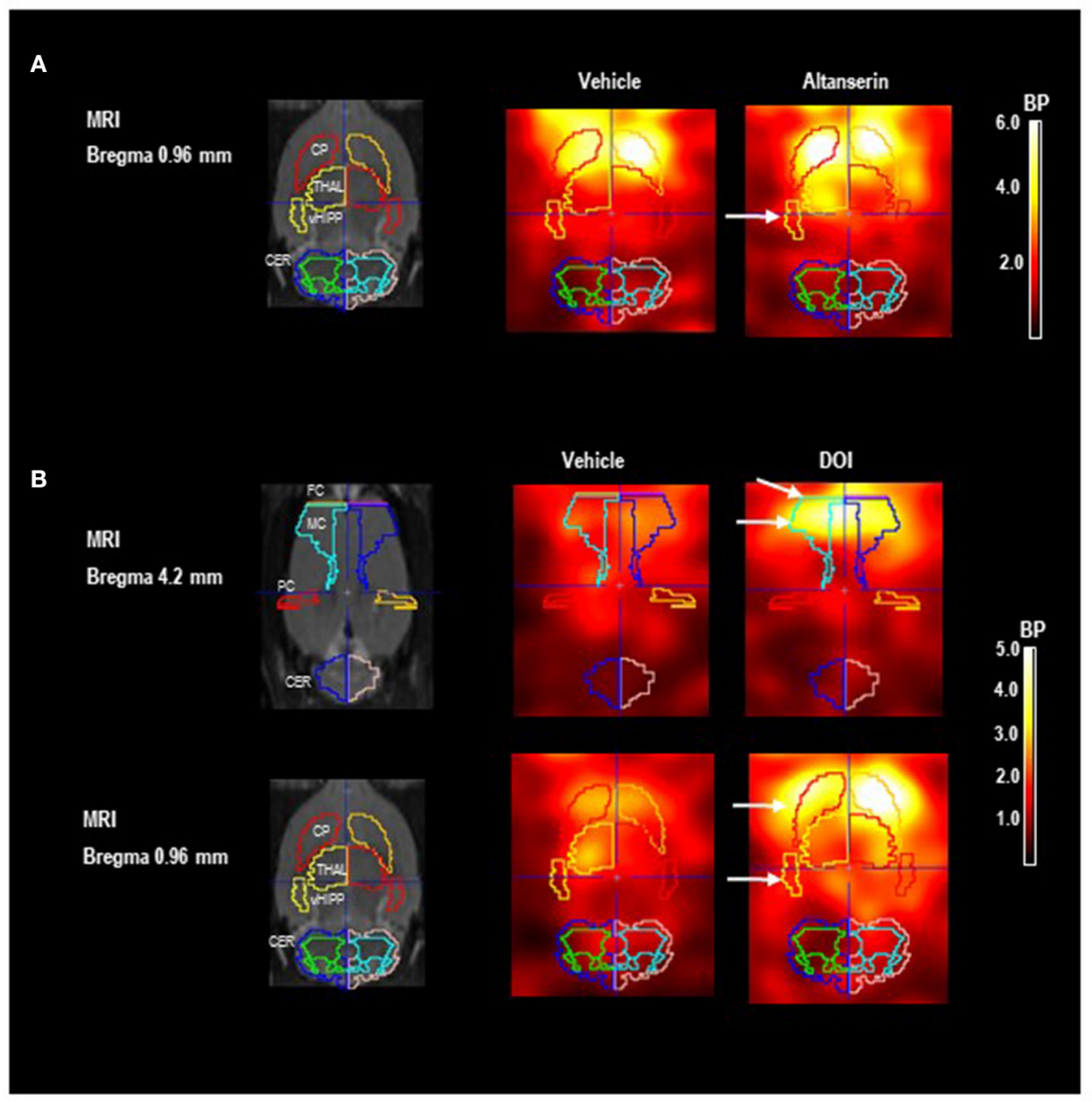

FIGURE 2 | Paxinos standard rat brain MRI and $\mathrm{D}_{2 / 3} \mathrm{R}$ single-photon emission computed tomography (SPECT) images after 5-HT $2 \mathrm{~A}$ receptor antagonistic (A) and agonistic treatment (B) with [ ${ }^{123}$ l]IBZM as a radioligand. The left column shows Paxinos standard rat brain MR images (Schiffer et al., 2006) at different positions from bregma together with the standard volume of interest (VOI) templates provided by PMOD. The middle column shows coronal SPECT slices in two characteristic rats after pretreatment with (A) dimethyl sulfoxide (DMSO) and (B) saline as vehicle at the same positions from bregma depicted in the left column. The right column shows SPECT slices in the same rats after pretreatment with (A) $10 \mathrm{mg} / \mathrm{kg}$ of altanserin and (B) $0.5 \mathrm{mg} / \mathrm{kg}$ of 2,5-dimethoxy-4-iodoamphetamine (DOI) at the same positions from bregma. Increases of $\left[{ }^{123} \mathrm{l}\right]$ IBZM accumulation are marked by white arrows. SPECT images show binding potentials (BPs). It is understood that the calculation of BPs is only valid for regions with specific radioligand binding. Analysis and image algebra were performed with PMOD (version 3.5, PMOD Technologies Ltd., Zürich, Switzerland). CER, cerebellum; CP, caudate putamen; FC, frontal cortex; MC, motor cortex; PC, parietal cortex; THAL, thalamus; vHIPP, ventral hippocampus.

transformations were saved. The SPECT image as coregistered with the MRI was imported using these transformations, which allowed creation of an overlay with the Paxinos standard rat brain MRI. On these overlays, the following volumes of interest (VOIs) were defined: NAC, CP, THAL, SN/VTA, FC, MC, PC, dHIPP, and vHIPP. According to the rat brain atlas (Paxinos and Watson, 2014), all these regions have maximum craniocaudal and one-sided mediolateral and dorsoventral (vertical or oblique) dimensions in the range of or beyond the spatial resolution of the imaging system (3.4 mm for ${ }^{123} \mathrm{I}$; Schramm et al., 2000).

Regional binding potentials (BPs) were calculated according to the simplified reference tissue model (Ichise et al., 2001) by computing ratios of the radioactivity counts measured in the specifically bound compartments (NAC, CP, THAL, SN/VTA, FC, MC, PC, dHIPP, and vHIPP) to the radioactivity counts in the cerebellar reference VOI. Although the cerebellum receives 5-HTergic afferents from raphe nuclei (Torigoe et al., 1986), it is suitable as a reference region, since it contains practically no $\mathrm{D}_{2 / 3} \mathrm{R}$ binding sites (Camps et al., 1989).

\section{Statistical Analysis $D_{2 / 3} R$ Imaging Studies}

Distributions of regional BPs after 5-HTergic challenges as well as vehicles were tested for normality with the non-parametric Kolmogorov-Smirnov test $(\alpha \leq 0.05)$. The regional BPs were not uniformly normally distributed after ALT or DMSO $(0.001 \leq p \leq$ $0.200)$ nor after DOI or SAL $(0.008 \leq p \leq 0.200)$.

Medians and interquartile ranges (25th/75th and 5th/95th percentiles) of regional BPs were calculated for each treatment. 


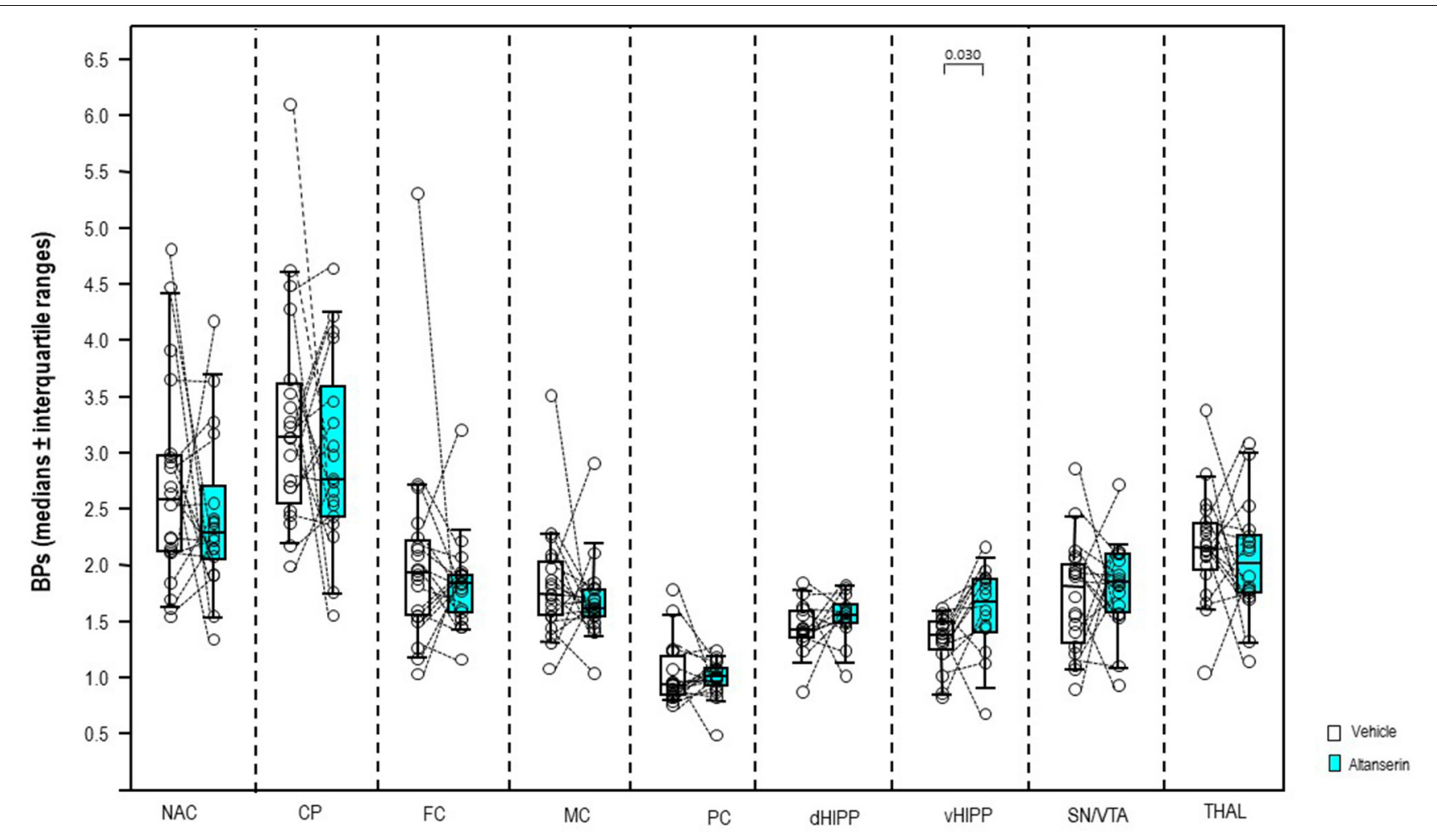

FIGURE 3 | Binding potentials (BPs) after altanserin (10 mg/kg; turquoise) and vehicle (dimethyl sulfoxide; white). Rendered are medians and 25th/75th (boxes) and 9th/95th quartiles (whiskers). The circles represent the individual animals. Treatments were compared with the Wilcoxon signed-rank test for paired samples (two-tailed, $\alpha=0.05)$. The significant $p$-values are given. CP, caudate putamen; dHIPP, dorsal hippocampus; FC, frontal cortex; MC, motor cortex; NAC, nucleus accumbens; PC, parietal cortex; SN/NTA, substantia nigra/ventral tegmental area; THAL, thalamus (THAL); vHIPP, ventral hippocampus.

Moreover, percentual differences of BPs after ALT and DOI relative to DMSO and SAL, respectively, were computed.

A two-way analysis of variance (ANOVA) was conducted with the factors "brain region" and "treatment" $(\alpha \leq 0.05)$. Regional BPs were compared between 5-HTergic challenge and the respective vehicle (ALT vs. DMSO, and DOI vs. SAL) with the non-parametric Wilcoxon signed-rank test for paired samples (two-tailed, $\alpha \leq 0.05$ ).

Statistic calculations were performed with SigmaStat (version 3.5, Systat Software Inc., Erkrath, Germany).

\section{Network Analyses}

With this mode of analysis, the network structure of variablespredefined so-called "nodes" - can be analyzed by estimating path coefficients, which describe the "strength" of the individual connections. Here, we separately assessed the associations between $\mathrm{D}_{2 / 3} \mathrm{R}$ binding in NAC, CP, THAL, SN/VTA, FC, MC, PC, dHIPP, and vHIPP after 5-HTergeic challenges and the respective vehicles. Covariance matrices were estimated with gaussian graphical models employing graphical $\mathrm{L}_{1}$ (lasso) regularized regression in order to increase matrix sparsity (Friedman et al., 2008). The tuning parameter was chosen using the extended Bayesian information criterion (EBICglasso). EBICglassos were computed using JASP (version 0.10.2.0, (C) 2013-2019 University of Amsterdam).

\section{Behavioral Studies}

For each pretreatment condition (ALT, DOI, DMSO, and SAL), distributions of behavioral parameters (duration and frequencies of ambulation, sitting, rearing, and head-shoulder motility) after 5 -HTergic challenges as well as vehicles were tested for normality with the non-parametric Kolmogorov-Smirnov test $(\alpha \leq 0.05)$. Since none of the behavioral parameters was uniformly normally distributed in any of the pretreatment conditions $(0.0001 \leq p$ $\leq 0.2$ ), behaviors in each 5 -min bin were compared between 5 HTergic challenge and treatment with the respective vehicle (ALT vs. DMSO, and DOI vs. SAL) with the Mann-Whitney $U$-test for unrelated samples (two-sided, $\alpha \leq 0.05$ ). Statistic calculations were performed with SigmaStat (version 3.5, Systat Software Inc., Erkrath, Germany).

\section{RESULTS}

\section{$D_{2 / 3} R$ Binding}

\section{5-HTergic Treatments vs. Vehicle}

Figures 2A,B show images of the Paxinos standard rat brain MRI atlas (Schiffer et al., 2006) at different positions from the bregma together with the standard VOI templates provided by PMOD (left column). The next two columns show characteristic images of regional $\left[{ }^{123} \mathrm{I}\right] \mathrm{IBZM}$ accumulations on coronal slices after treatment with vehicle [DMSO (A) or SAL (B); middle] and 


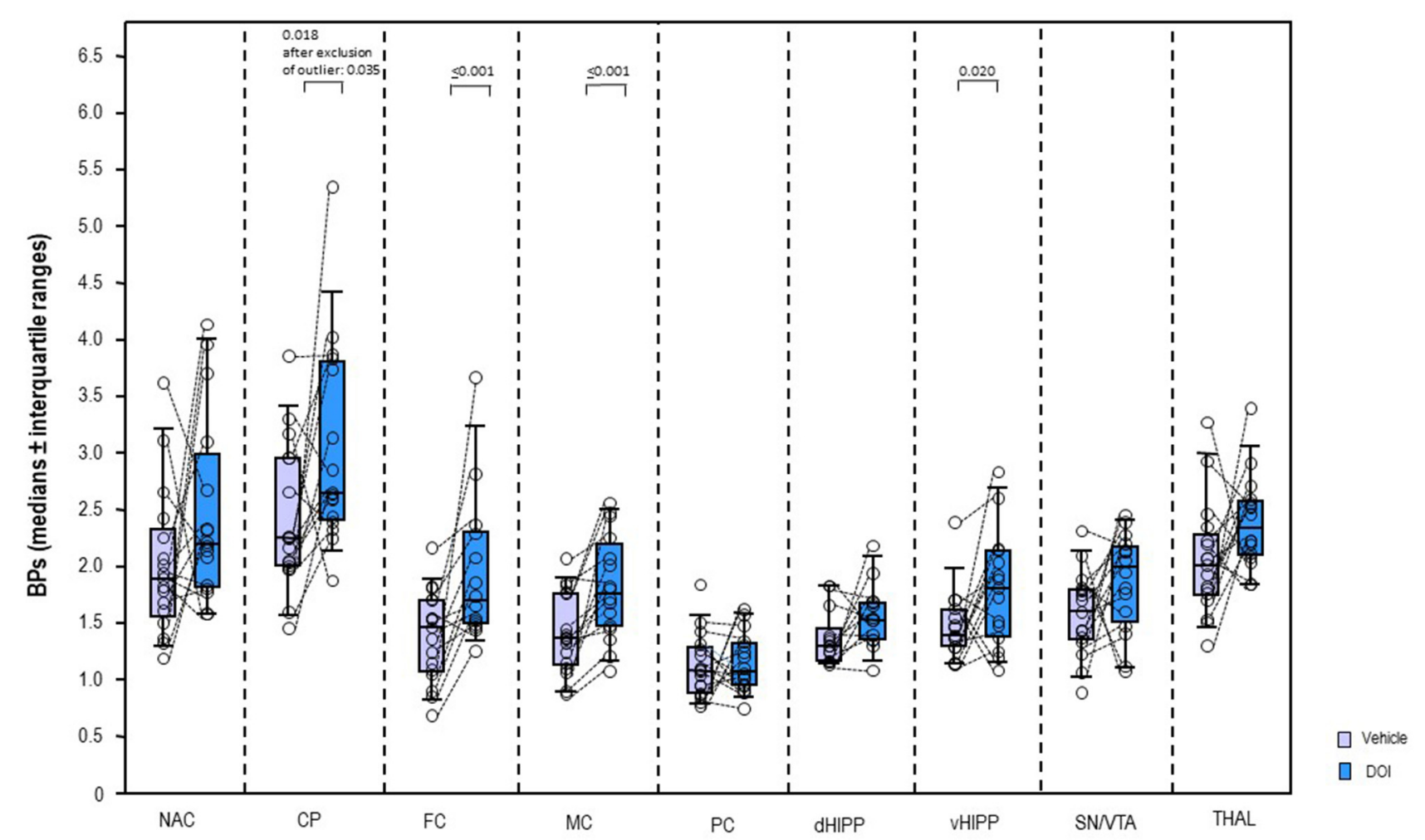

FIGURE 4 | Binding potentials (BPs) after 2,5-dimethoxy-4-iodoamphetamine (DOI; 0.5 mg/kg; blue) and vehicle (saline; light purple). Rendered are medians and 25th/75th (boxes) and 9th/95th quartiles (whiskers). The circles represent the individual animals. Treatments were compared with the Wilcoxon signed-rank test for paired samples (two-tailed, $\alpha=0.05$ ). The significant $p$-values are given. CP, caudate putamen; dHIPP, dorsal hippocampus; FC, frontal cortex; MC, motor cortex; NAC, nucleus accumbens; PC, parietal cortex; SN/NTA, substantia nigra/ventral tegmental area; THAL, thalamus (THAL); vHIPP, ventral hippocampus.

after 5-HTergic challenge [ALT (A) or DOI (B); right], at the positions from the bregma depicted in the left column. Scans after vehicle and the respective 5-HTergic challenge stem from the same rat.

The two-way ANOVA yielded significant effects of "treatment" ( $p<0.0001)$ and "brain region" $(p<0.001)$ as well as a significant interaction "treatment $\times$ region" $(p=0.024)$.

After $10 \mathrm{mg} / \mathrm{kg}$ of ALT (Figure 3), BP was significantly augmented in vHIPP $(+22 \%, p=0.030)$ relative to vehicle. No significant alterations were observed in the other brain regions $(0.268 \leq p \leq 0.899)$.

In a dose of $0.5 \mathrm{mg} / \mathrm{kg}$, DOI (Figure 4) induced significant increases of the BPs in CP $(+17 \%, p=0.018$; after exclusion of the outlier: $p=0.035)$, FC $(+16 \%, p \leq 0.001), \mathrm{MC}(+29 \%, p \leq$ $0.001)$, and vHIPP $(+30 \%, p=0.020)$. No significant alterations were observed in the other brain regions $(0.107 \leq p \leq 0.847)$.

\section{Network Analyses}

Network analyses of the BPs obtained after treatment with DMSO yielded 23 out of 36 possible connections (Figure 5A; sparsity, 0.361 ), while after treatment with ALT, 30 out of 36 possible connections were obtained (Figure 5B), decreasing sparsity to 0.167. The individual path coefficients (c) obtained after DMSO and ALT are given in Tables 1, 2, respectively. Common to both treatments were strong positive connections $(c>0.100)$ between NAC and CP, FC and MC, dHIPP and vHIPP, CP and THAL, SN/VTA and THAL, and SN/VTA and vHIPP, as well as negative connections between FC and vHIPP, and SN/VTA and PC. Moreover, connections between NAC and THAL and FC and PC were positive after DMSO but negative after ALT. Conversely, the connection between NAC and PC was negative after DMSO, but positive after ALT. Besides, the positive connections between CP and SN/VTA, CP and FC, CP and MC, and THAL and vHIPP as well as PC and dHIPP obtained after DMSO were not existent any more after treatment with ALT. Instead, positive connections between NAC and vHIPP, SN/VTA and MC, THAL and PC, THAL and dHIPP, MC and PC, MC and AHIPP, and MC and vHIPP as well as negative connections between NAC and dHIPP and PC and vHIPP were existent.

Network analyses of the BPs obtained after treatment with SAL yielded 23 out of 36 possible connections (Figure 5C; sparsity, 0.361), while after treatment with DOI (Figure 5D), 29 out of 36 possible connections were obtained (Figure 5B), decreasing sparsity to 0.194 . The individual path coefficients obtained after SAL and DOI are given in Tables 3, 4, respectively. Common to both treatments were strong positive connections (c > 0.100) between NAC and CP, NAC and SN/VTA, SN/VTA and vHIPP, THAL and FC, and THAL and dHPP as well as 


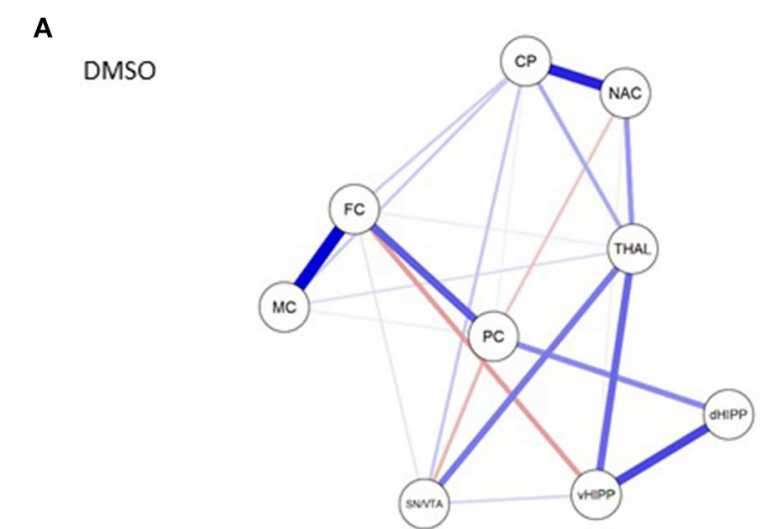

B

ALT

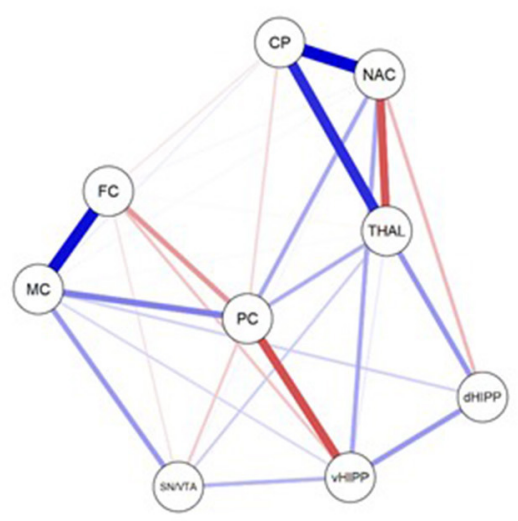

C

SAL

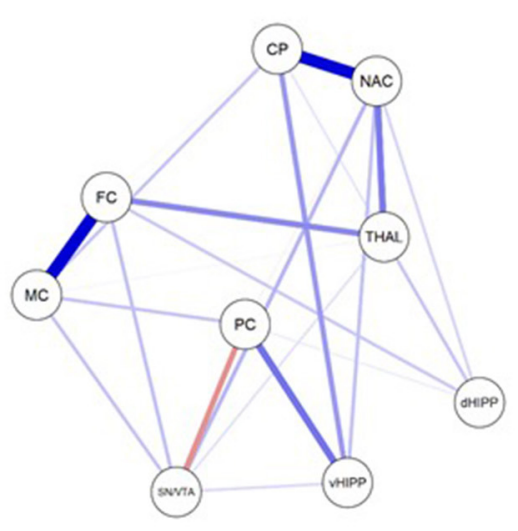

D

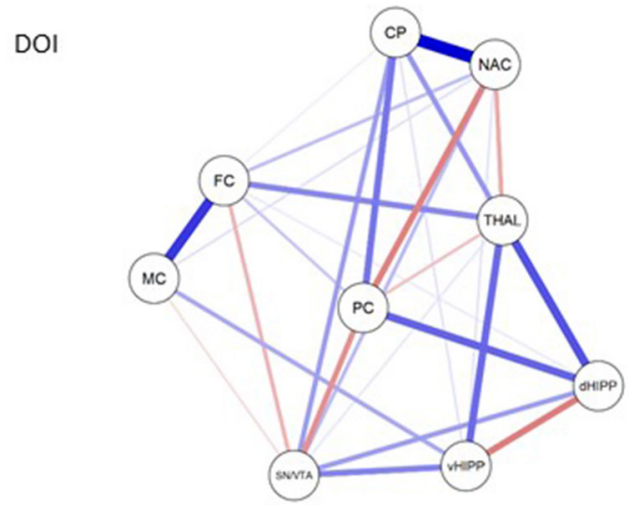

FIGURE 5 | Connections between nucleus accumbens (NAC), caudate putamen (CP), thalamus (THAL), substantia nigra/ventral tegmental area (SN/VTA), frontal cortex (FC), motor cortex (MC), parietal cortex (PC), dorsal hippocampus (dHIPP), and ventral hippocampus (VHIPP) obtained after (A) dimethyl sulfoxide (DMSO), (B) altanserin (ALT), (C) saline (SAL), and (D) 2,5-dimethoxy-4-iodoamphetamine (DOI) application. Positive and negative associations are represented by blue and red lines, respectively. The size of the lines indicates the strength of the individual connections. Models were estimated with JASP (version 0.10.2.0, ๑ 2013-2019 University of Amsterdam).

FC and MC and a strong negative association between SN/VTA and PC. After SAL, strong positive connections were obtained between NAC and THAL, NAC and PC, SN/VTA and FC, and SN/VTA and MC, which became negative after treatment with DOI. Moreover, after SAL, strong positive connections were found between NAC and dHIPP, NAC and vHIPP, CP and MC, CP and vHIPP, FC and DHIPP, MC and PC, and PC and VHIPP, which were not existent or much weaker after DOI. In turn, strong positive connections between NAC and FC, CP and SN/VTA, CP and THAL, CP and PC, CP and dHIPP, SN/VTA and dHIPP, THAL and vHIPP, PC and dHIPP, FC and PC, and MC and vHIPP and strong negative connections between THAL and PC as well as dHIPP and vHIPP were added.

\section{Motor and Exploratory Behaviors}

Overall activity (Figure 6) was lower after ALT compared with DMSO in all individual 5 -min bins $(0.0001 \leq p \leq$ 0.042). After DOI, it fell short relative to SAL from $\mathrm{min}$
1 to $20(0.0001 \leq p \leq 0.029)$ and from $\min 26$ to $30(p=0.017)$.

Inspection of the individual behavioral parameters yielded decreased duration and frequency of ambulation (Figures 7A,B) after ALT relative to DMSO from min 1 to 20 (duration, 0.0001 $\leq p \leq 0.46$; frequency, $0.0001 \leq p \leq 0.036$ ). Moreover, after ALT, animals ambulated for a shorter time compared with DMSO from min 41 to 45 ( $p=0.042)$. Comparisons between DOI and SAL merely yielded a decreased duration of ambulation after the former relative to the latter treatment from $\min 1$ to 5 ( $p=0.007)$.

Sitting duration (Figure 8A) was increased after ALT relative to DMSO in all bins $(0.0001 \leq p \leq 0.009)$. There were no between-group differences, however, of sitting frequency (Figure 8B). Conversely, sitting duration was unaltered after DOI compared with SAL, whereas sitting frequency was increased from $\min 11$ to $30(0.0001 \leq p \leq 0.002)$.

Rearing duration (Figure 9A) as well as rearing frequency (Figure 9B) was decreased after pretreatment with ALT relative to DMSO from min 6 to 20 and from min 26 to 30 (duration, $0.0001 \leq p \leq 0.013$; frequency, $0.0001 \leq p \leq 0.018)$. After 
TABLE 1 | Path coefficient matrix after treatment with dimethyl sulfoxide (DMSO) obtained with EBICglasso modeling of $\mathrm{D}_{2 / 3} \mathrm{R}$ binding potentials in nucleus accumbens (NAC), caudate putamen (CP), thalamus (THAL), substantia nigra/ventral tegmental area (SN/NTA), frontal cortex (FC), motor cortex (MC), parietal cortex (PC), dorsal hippocampus (dHIPP), and ventral hippocampus (vHIPP).

\begin{tabular}{|c|c|c|c|c|c|c|c|c|c|}
\hline & NAC & CP & THAL & SN/VTA & FC & MC & PC & dHIPP & vHIPP \\
\hline NAC & 0.000 & 0.578 & 0.268 & 0.000 & 0.000 & 0.000 & -0.148 & 0.000 & -0.053 \\
\hline $\mathrm{CP}$ & & 0.000 & 0.218 & 0.148 & 0.134 & 0.142 & 0.043 & 0.000 & 0.000 \\
\hline THAL & & & 0.000 & 0.350 & 0.056 & 0.093 & 0.000 & 0.004 & 0.395 \\
\hline SN/NTA & & & & 0.000 & 0.073 & 0.000 & -0.187 & 0.000 & 0.114 \\
\hline FC & & & & & 0.000 & 0.679 & 0.427 & 0.000 & -0.253 \\
\hline $\mathrm{MC}$ & & & & & & 0.000 & 0.051 & 0.000 & 0.000 \\
\hline PC & & & & & & & 0.000 & 0.306 & 0.000 \\
\hline dHIPP & & & & & & & & 0.000 & 0.481 \\
\hline VHIPP & & & & & & & & & 0.000 \\
\hline
\end{tabular}

TABLE 2 | Path coefficient matrix after treatment with altanserin obtained with EBICglasso modeling of $D_{2 / 3} R$ binding potentials in nucleus accumbens (NAC), caudate putamen (CP), thalamus (THAL), substantia nigra/ventral tegmental area (SN/NTA), frontal cortex (FC), motor cortex (MC), parietal cortex (PC), dorsal hippocampus (dHIPP), and ventral hippocampus (vHIPP).

\begin{tabular}{|c|c|c|c|c|c|c|c|c|c|}
\hline & NAC & $\mathrm{CP}$ & THAL & SN/VTA & FC & MC & PC & dHIPP & vHIPP \\
\hline NAC & 0.000 & 0.866 & -0.567 & 0.033 & 0.030 & 0.028 & 0.287 & -0.230 & 0.292 \\
\hline $\mathrm{CP}$ & & 0.000 & 0.713 & 0.000 & -0.082 & 0.057 & -0.133 & 0.000 & 0.000 \\
\hline THAL & & & 0.000 & 0.155 & -0.025 & 0.018 & 0.264 & 0.350 & 0.069 \\
\hline SN/VTA & & & & 0.000 & -0.094 & 0.337 & -0.166 & 0.000 & 0.248 \\
\hline FC & & & & & 0.000 & 0.822 & -0.342 & 0.000 & -0.587 \\
\hline $\mathrm{MC}$ & & & & & & 0.000 & 0.427 & 0.153 & 0.124 \\
\hline PC & & & & & & & 0.000 & 0.000 & -0.587 \\
\hline dHIPP & & & & & & & & 0.000 & 0.344 \\
\hline vHIPP & & & & & & & & & 0.000 \\
\hline
\end{tabular}

pretreatment with DOI, both rearing duration and frequency were reduced relative to SAL from min 6 to 15 and min 26 to 30 (duration, $0.0001 \leq p \leq 0.034$; frequency, $0.0001 \leq p \leq 0.031$ ).

After ALT, the frequency of head-shoulder motility (Figure 10B) was decreased throughout the whole testing time relative to DMSO $(0.0001 \leq p \leq 0.013)$. Except for the first 5-min bin, this also held for the duration of head-shoulder motility (Figure 10A; $0.0001 \leq p \leq 0.012$ ). After DOI, the frequency of head-shoulder motility was elevated relative to SAL from $\min 1$ to $5(p=0.001)$ and $\min 26$ to $30(p=0.048)$. An increase of duration of head-shoulder motility was observed from $\min 1$ to 10 ( $p=0.004$ and 0.003 , respectively).

\section{DISCUSSION}

\section{$D_{2 / 3} R$ Binding}

The present study presents the first in vivo imaging evidence on the effects of $5-\mathrm{HT}_{2} \mathrm{~A}$ antagonistic and agonistic challenges on subcortical and neocortical DA functions: systemic treatment with the $5-\mathrm{HT}_{2 \mathrm{~A}} \mathrm{R}$ antagonist ALT in a dose of $10 \mathrm{mg} / \mathrm{kg}$ significantly increased $\mathrm{D}_{2 / 3} \mathrm{R}$ binding in vHIPP $(+22 \%)$ relative to vehicle, while systemic treatment with the $5-\mathrm{HT}_{2 \mathrm{~A}} \mathrm{R}$ agonist DOI in a dose of $0.5 \mathrm{mg} / \mathrm{kg}$ significantly augmented $\mathrm{D}_{2 / 3} \mathrm{R}$ binding $\mathrm{CP}(+17 \%), \mathrm{FC}(+16 \%), \mathrm{MC}(+29 \%)$, and vHIPP (+30\%).
In previous studies on rats, systemic L-DOPA as well as $\mathrm{GABA}_{\mathrm{A}} \mathrm{R}$ agonist and $\mathrm{N}$-methyl-D-aspartate (NMDA)R antagonist treatment reduced $\left[{ }^{123}\right]$ IBZM binding, whereas $\mathrm{GABA}_{\mathrm{A}} \mathrm{R}$ antagonist and NMDAR agonist treatment elevated $\left[{ }^{123}\right]$ IBZM binding to the neostriatal $\mathrm{D}_{2 / 3} \mathrm{R}$ (Nikolaus et al., 2016, 2018, 2019). Since [ $\left.{ }^{123}\right]$ IBZM competes with endogenous DA molecules for $\mathrm{D}_{2 / 3} \mathrm{R}$ binding sites, the observed decreases and increases of $\mathrm{D}_{2 / 3} \mathrm{R}$ binding may be interpreted to reflect increases and decreases, respectively, of synaptic DA (Laruelle, 2000). Hence, it can be assumed that, also in the present study, the regional elevations of $\mathrm{D}_{2 / 3} \mathrm{R}$ binding elicited by ALT and DOI were due to decreased DA concentrations in these areas.

Under the present experimental conditions, we observed a significant elevation of $\mathrm{D}_{2 / 3} \mathrm{R}$ binding (indicative of decreased DA levels) in the vHIPP after $10 \mathrm{mg} / \mathrm{kg}$ of ALT. However, in contrast to the results obtained by Dewey et al. (1995) on baboons and rats after 1 and $20 \mathrm{mg} / \mathrm{kg}$ of ALT using PET and in vivo microdialysis, respectively, no significant decreases of neostriatal $\mathrm{D}_{2 / 3} \mathrm{R}$ binding were detected. This may be accounted for by the differences of method: (1) non-invasive in vivo imaging of rats vs. invasive in vivo microdialysis of rats in the study of Dewey et al. (1995), (2) anesthetized rats vs. freely moving rats in the study of Dewey et al. (1995), (3) adult rats (mean weight, $466 \mathrm{~g}$ ) vs. adolescent rats (200-300 g) in the study of Dewey et al. (1995), and, finally, (4) in vivo imaging of rats vs. in vivo imaging of 
TABLE 3 | Path coefficient matrix after treatment with saline obtained with EBICglasso modeling of $D_{2 / 3} R$ binding potentials in nucleus accumbens (NAC), caudate putamen (CP), thalamus (THAL), substantia nigra/ventral tegmental area (SN/NTA), frontal cortex (FC), motor cortex (MC), parietal cortex (PC), dorsal hippocampus (dHIPP), and ventral hippocampus (vHIPP).

\begin{tabular}{|c|c|c|c|c|c|c|c|c|c|}
\hline & NAC & CP & THAL & SN/VTA & FC & MC & PC & dHIPP & VHIPP \\
\hline NAC & 0.000 & 0.592 & 0.307 & 0.169 & 0.000 & 0.000 & -0.033 & 0.103 & 0.145 \\
\hline $\mathrm{CP}$ & & 0.000 & 0.065 & 0.000 & 0.016 & 0.132 & 0.000 & 0.000 & 0.234 \\
\hline THAL & & & 0.000 & 0.071 & 0.275 & 0.022 & 0.000 & 0.132 & 0.000 \\
\hline SN/NTA & & & & 0.000 & 0.146 & 0.138 & -0.255 & 0.000 & 0.089 \\
\hline FC & & & & & 0.000 & 0.604 & 0.000 & 0.126 & 0.000 \\
\hline dHIPP & & & & & & & & 0.000 & 0.000 \\
\hline vHIPP & & & & & & & & & 0.000 \\
\hline
\end{tabular}

TABLE 4 | Path coefficient matrix after treatment with 2,5-dimethoxy-4-iodoamphetamine (DOI) obtained with EBICglasso modeling of $D_{2 / 3} R$ binding potentials in nucleus accumbens (NAC), caudate putamen (CP), thalamus (THAL), substantia nigra/ventral tegmental area (SN/VTA), frontal cortex (FC), motor cortex (MC), parietal cortex (PC), dorsal hippocampus (dHIPP), and ventral hippocampus (vHIPP).

\begin{tabular}{|c|c|c|c|c|c|c|c|c|c|}
\hline & NAC & CP & THAL & SN/VTA & FC & MC & PC & dHIPP & vHIPP \\
\hline NAC & 0.000 & 0.648 & -0.209 & 0.168 & 0.157 & 0.077 & -0.310 & 0.000 & 0.047 \\
\hline CP & & 0.000 & 0.254 & 0.242 & 0.044 & 0.000 & 0.341 & 0.134 & 0.073 \\
\hline THAL & & & 0.000 & 0.060 & 0.298 & 0.000 & -0.144 & 0.433 & 0.368 \\
\hline SN/VTA & & & & 0.000 & -0.183 & -0.084 & -0.272 & 0.240 & 0.304 \\
\hline FC & & & & & 0.000 & 0.503 & 0.134 & 0.055 & 0.000 \\
\hline $\mathrm{MC}$ & & & & & & 0.000 & 0.000 & 0.000 & 0.074 \\
\hline PC & & & & & & & 0.000 & 0.390 & 0.000 \\
\hline dHIPP & & & & & & & & 0.000 & -0.321 \\
\hline vHIPP & & & & & & & & & 0.000 \\
\hline
\end{tabular}

baboons in the study of Dewey et al. (1995). Another likely reason might be the dosage, since Dewey et al. (1995) applied either a tenth of the dose or twice the dose (1 or $20 \mathrm{mg} / \mathrm{kg}$, respectively) administered in our investigation. In order to shed further light on the impact of dosage, a dose-response curve should be established by future imaging or in vivo microdialysis studies after increasing doses of ALT.

The present findings showed significant increases of $D_{2 / 3} R$ binding (indicative of decreased DA levels) after systemic DOI in $\mathrm{CP}, \mathrm{FC}, \mathrm{MC}$, and vHIPP. Since the affinity of DOI for the $5-\mathrm{HT}_{2 \mathrm{~A}} \mathrm{R}$ binding site exceeds its affinity for the $5-\mathrm{HT}_{2 \mathrm{C}} \mathrm{R}$ by one order of magnitude (Canal et al., 2013), and $\mathrm{HT}_{2 \mathrm{C}} \mathrm{R}$ is also related to DA efflux (Alex et al., 2005), it cannot be entirely excluded that the effects of DOI may have also partially been induced by $5-\mathrm{HT}_{2} \mathrm{C}$ action. The present result of decreased $\mathrm{DA}$ in the $\mathrm{CP}$ agrees with the outcome of a previous in vivo microdialysis study, reporting a reduction of striatal DA efflux upon infusion of DOI $(10$ and $20 \mu \mathrm{M})$ into this region $(\mathrm{Ng}$ et al., 1999). Apart from the lack of a significant alteration of $\mathrm{D}_{2 / 3} \mathrm{R}$ binding in the NAC (after DOI in a dose of $2 \mathrm{mg} / \mathrm{kg}$ i.p.), which was also reported by Ichikawa and Meltzer (1995), our findings on $\mathrm{D}_{2 / 3} \mathrm{R}$ binding, however, are not consistent with the precedent microdialysis findings after systemic application of DOI (Gudelsky et al., 1994; Ichikawa and Meltzer, 1995; Gobert and Millan, 1999), which reported either no effect on DA levels in the CP (2 mg/kg i.p., Gudelsky et al., 1994; $2.5 \mathrm{mg} / \mathrm{kg}$ i.p., Ichikawa and Meltzer, 1995) or increased DA levels in the FC (0.1-10 mg/kg s.c., Gobert and Millan, 1999). The dose of 0.5 $\mathrm{mg} / \mathrm{kg}$ of DOI lies in the range of doses $(0.1-10 \mathrm{mg} / \mathrm{kg}$ ) applied in the other investigations (Gudelsky et al., 1994; Ichikawa and Meltzer, 1995; Gobert and Millan, 1999), which precludes dosage as a relevant factor for the inconsistency of outcomes. However, a likely reason for the observed discrepancy, also here, are the methodological differences: we employed a non-invasive in vivo imaging approach in contrast to the invasive microdialysis studies of Gudelsky et al. (1994), Ichikawa and Meltzer (1995), and Gobert and Millan (1999). Moreover, we used adult rats in contrast to the adolescent animals employed in the other investigations (Gudelsky et al., 1994, 225-300 g; Ichikawa and Meltzer, 1995, 200-300 g; Gobert and Millan, 1999, 200-220 g).

\section{5- $\mathrm{HT}_{2 \mathrm{~A}} \mathrm{R}$ Agonistic and Antagonistic Actions Within Cerebral Networks}

After 5-HTergic challenges as well as vehicles, network analyses of regional $\mathrm{D}_{2 / 3} \mathrm{R}$ BPs indicated distinct relations between the individual brain regions. Thereby, irrespective of the applied treatment, the same framework of functional connections between NAC and CP, NAC and THAL, CP and THAL, SN/VTA and THAL, SN/VTA and vHIPP, and FC and MC was obtained. Interestingly, however, after SAL, a strong positive connection 


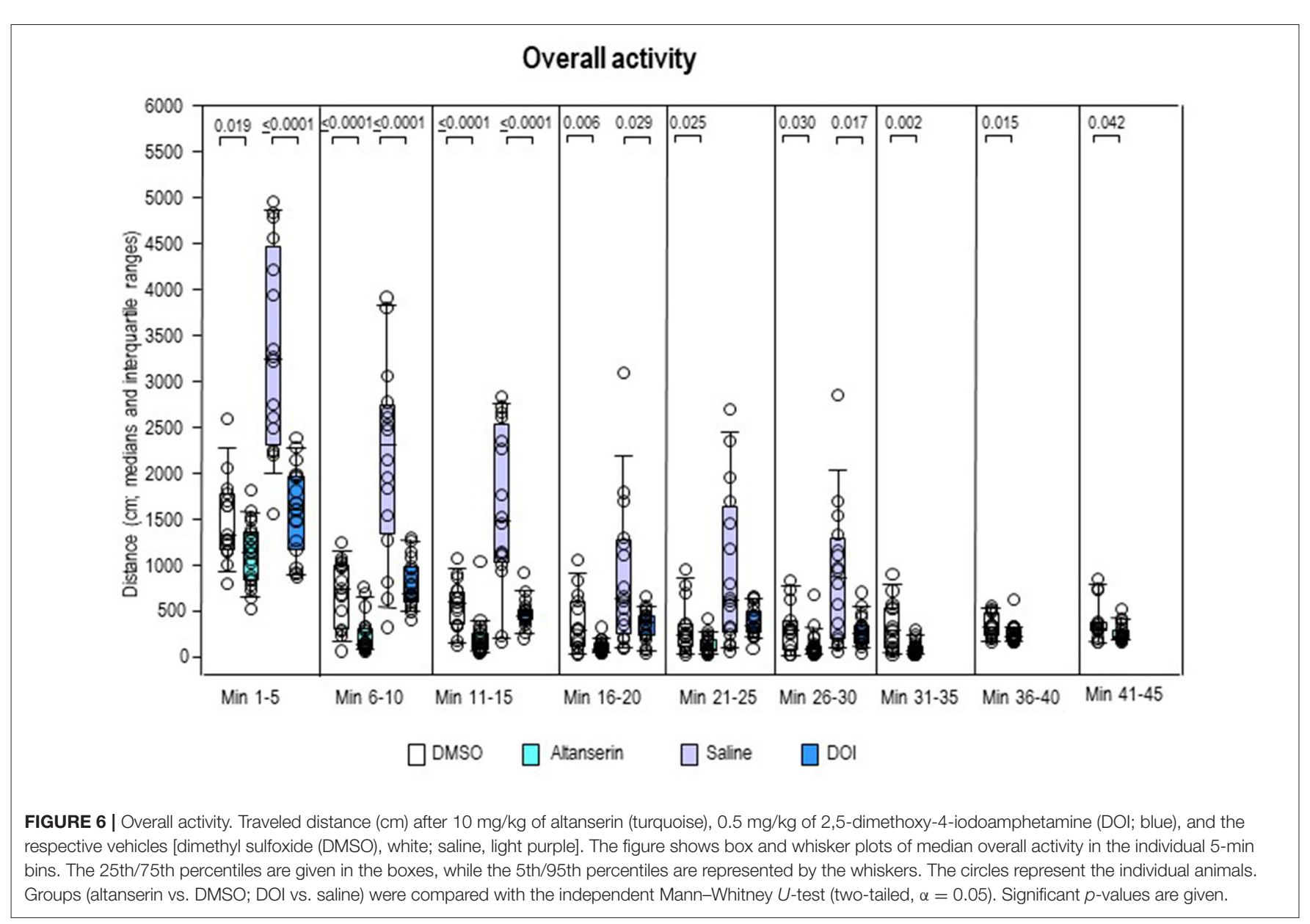

was found between NAC and THAL, which became negative after treatment with DOI. This also held for the connections between NAC and PC, SN/VTA and FC, and SN/VTA and MC. Furthermore, strong positive connections between NAC and FC, $\mathrm{CP}$ and SN/VTA, CP and THAL, CP and PC, CP and dHIPP, SN/VTA and dHIPP, THAL and vHIPP, PC and dHIPP, FC and $\mathrm{PC}$, and $\mathrm{MC}$ and VHIPP and strong negative connections between THAL and PC as well as dHIPP and vHIPP were added.

In the mammalian brain, 5-HTergic fibers extend to the SN and VTA (Oades and Halliday, 1987; Wirtshafter et al., 1987), which both express high amounts of $5-\mathrm{HT}_{2 \mathrm{~A}} \mathrm{R}$ binding sites (Doherty and Pickel, 2000; López-Giménez et al., 2001). 5$\mathrm{HT}_{2 \mathrm{~A}} \mathrm{R}$ action is known to increase the efflux of both GABA (Jiang et al., 2009) and GLU in the central nervous system (Meller et al., 2002). Previous studies with SB 242084 and Ro 60-0175 as receptor antagonist and agonist, respectively, additionally, have shown that the $5-\mathrm{HT}_{2} \mathrm{R}$ subtype decreased DA release in the $\mathrm{CP}$ by increasing GABAergic inhibition in the SN (Burke et al., 2014). Hence, it may be hypothesized that, after treatment with DOI, increased GABAergic inhibition outweighed GLUergic excitation in the sites of origin of DAergic fibers, leading to a reduction of DA efflux in the neostriatal target region as reflected by the elevation of radioligand binding to the striatal $\mathrm{D}_{2 / 3} \mathrm{R}$. The $5-\mathrm{HT}_{2 \mathrm{~A}} \mathrm{R}$ agonistic action exerted on the $\mathrm{CP}$ via the $\mathrm{SN}$, moreover, is indicated by the strong positive connection between both regions obtained in network analyses. The $\mathrm{CP}$ is inhibited by GABAergic microcircuits (Groves, 1983). Since it also receives ascending 5-HTergic fibers from the dorsal raphe nucleus (Steinbusch et al., 1980), it can be assumed that DOI, furthermore, facilitated the GABAergic inhibition exerted via these microcircuits, adding to the decrease of available DA. In the DAergic system, DA concentrations are regulated by autoreceptors of the $\mathrm{D}_{2} \mathrm{R}$ subtype localized at the presynaptic terminal (Langer, 1974). Remarkably, the DOIinduced reduction of available DA appeared to be so high that the inhibitory feedback mechanism of $\mathrm{D}_{2}$ autoreceptors was not effective in normalizing synaptic DA levels in the CP, at least in the present time window between DOI administration and $\mathrm{D}_{2 / 3} \mathrm{R}$ imaging at $75 \mathrm{~min}$ post-challenge.

The THAL (Moore et al., 1978) and neocortex also receive 5-HTergic projections (Kievit and Kuypers, 1975). Both regions exhibit high densities of GABA (Neto et al., 2006; Mann et al., 2009) and GLU binding sites (Salt et al., 1996; Sherman, 2014). Possibly, the 5- $\mathrm{HT}_{2 \mathrm{~A}} \mathrm{R}$ agonistic treatment increased GABAergic input from the THAL to the neocortex relative to GLUergic input, resulting in a net reduction of available DA in the FC and $\mathrm{MC}$ as reflected by the observed elevation of $\mathrm{D}_{2 / 3} \mathrm{R}$ binding in these regions. In turn, it may be assumed that decreased DAergic 
A

\section{Ambulation}

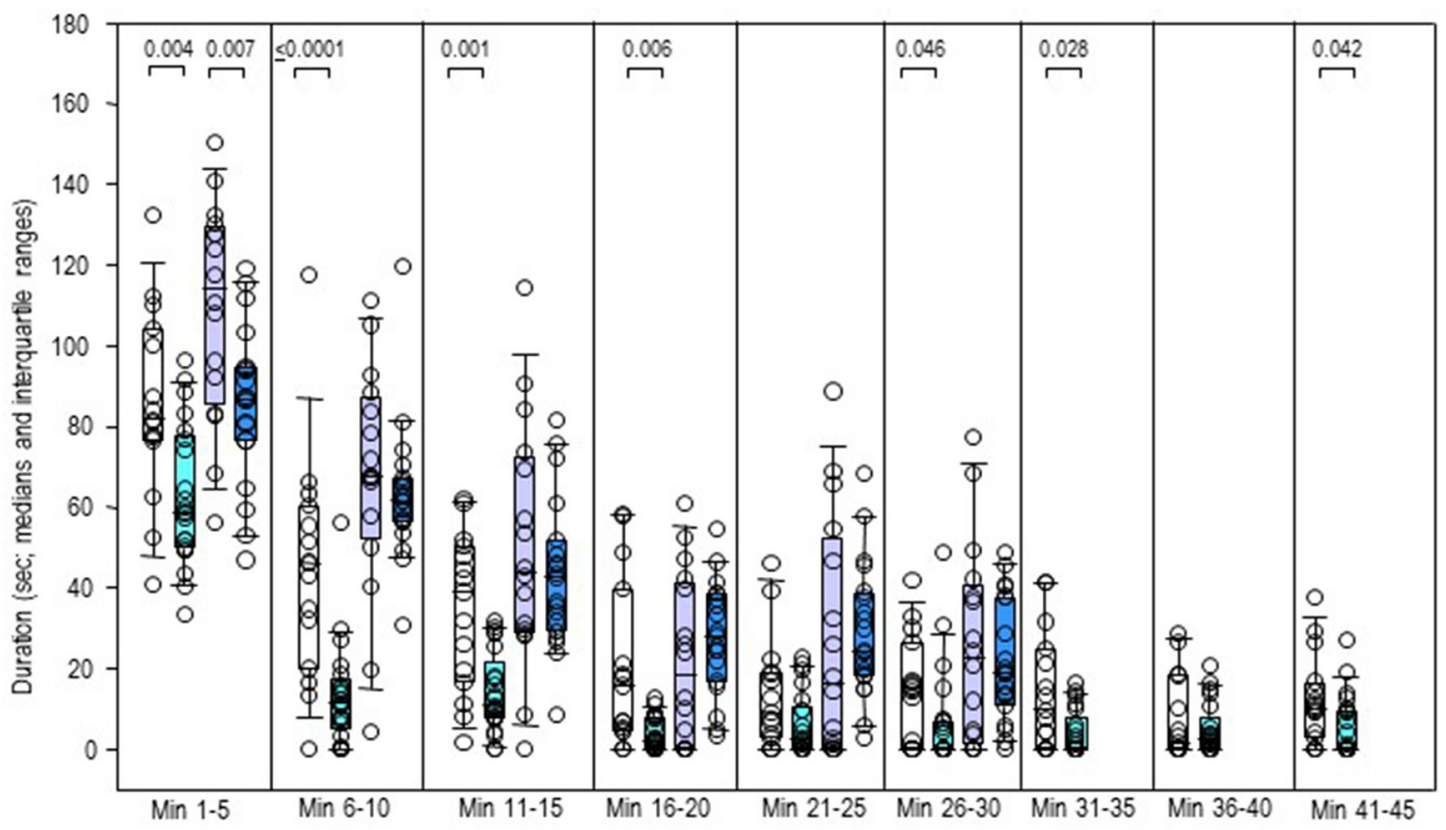

B

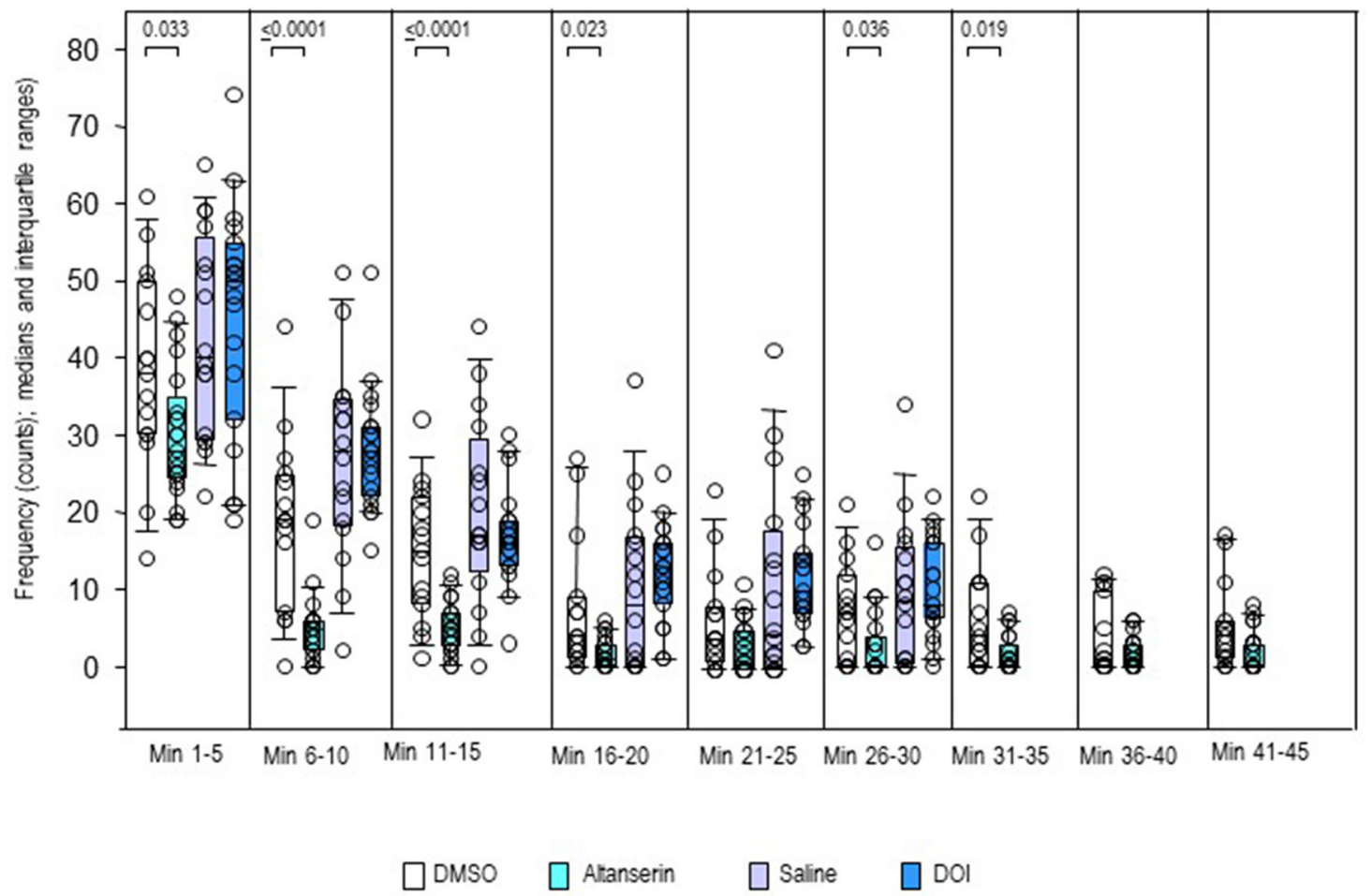

FIGURE 7 | Ambulation. Duration (s) and frequency (counts) after $10 \mathrm{mg} / \mathrm{kg}$ of altanserin (turquoise), $0.5 \mathrm{mg} / \mathrm{kg}$ of 2,5-dimethoxy-4-iodoamphetamine (DOI; blue), and the respective vehicles [dimethyl sulfoxide (DMSO), white; saline, light purple]. The figure shows box and whisker plots of median ambulation durations (A) and frequencies (B) in the individual 5-min bins. The 25th/75th percentiles are given in the boxes, while the 5th/95th percentiles are represented by the whiskers. The circles represent the individual animals. Groups (altanserin vs. DMSO; DOI vs. saline) were compared with the independent Mann-Whitney U-test (two-tailed, $\alpha=$ 0.05). Significant $p$-values are given. 
A

Sitting

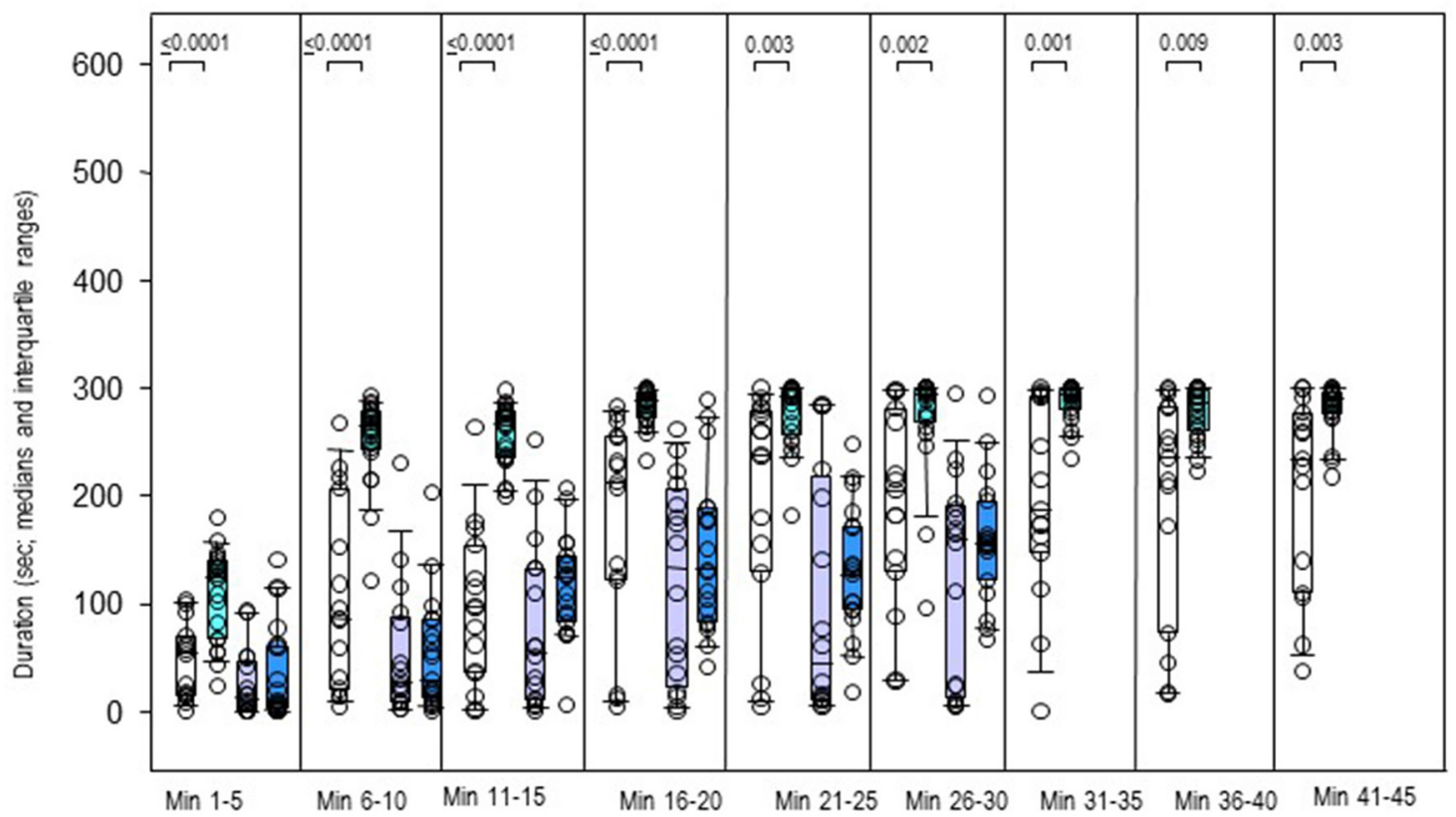

B

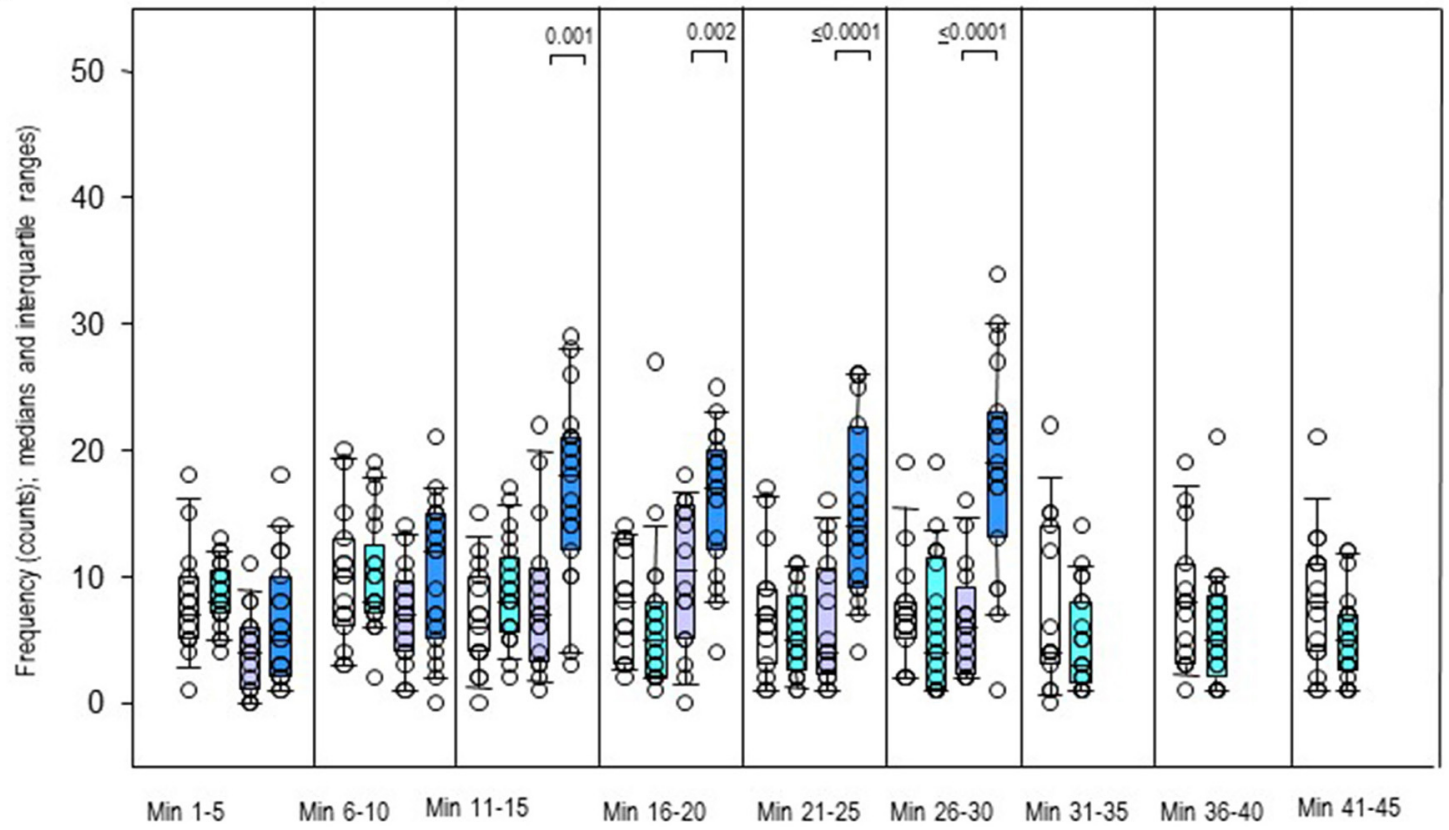

$\square$ DMSO $\square$ Allanserin $\square$ Saline $\square$ DOI

FIGURE 8 | Sitting. Duration (s) and frequency (counts) after $10 \mathrm{mg} / \mathrm{kg}$ of altanserin (turquoise), 0.5 mg/kg of 2,5-dimethoxy-4-iodoamphetamine (DOI; blue), and the respective vehicles [dimethyl sulfoxide (DMSO), white; saline, light purple]. The figure shows box and whisker plots of median sitting durations (A) and frequencies (B) in the individual 5-min bins. The 25th/75th percentiles are given in the boxes, while the 5th/95th percentiles are represented by the whiskers. The circles represent the individual animals. Groups (altanserin vs. DMSO; DOI vs. saline) were compared with the independent Mann-Whitney U-test (two-tailed, $\alpha=0.05$ ). Significant $p$-values are given. 
A

\section{Rearing}

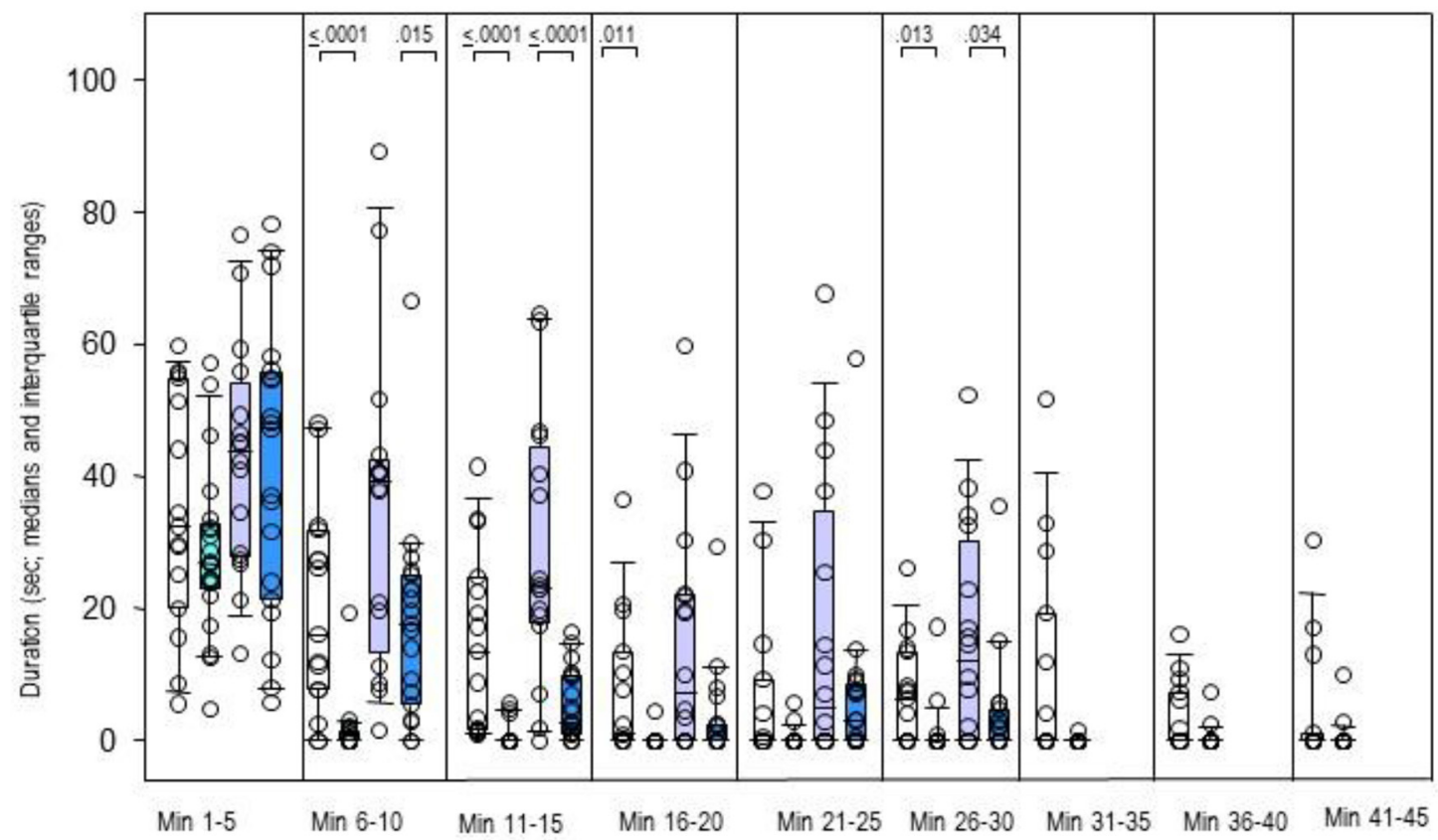

B

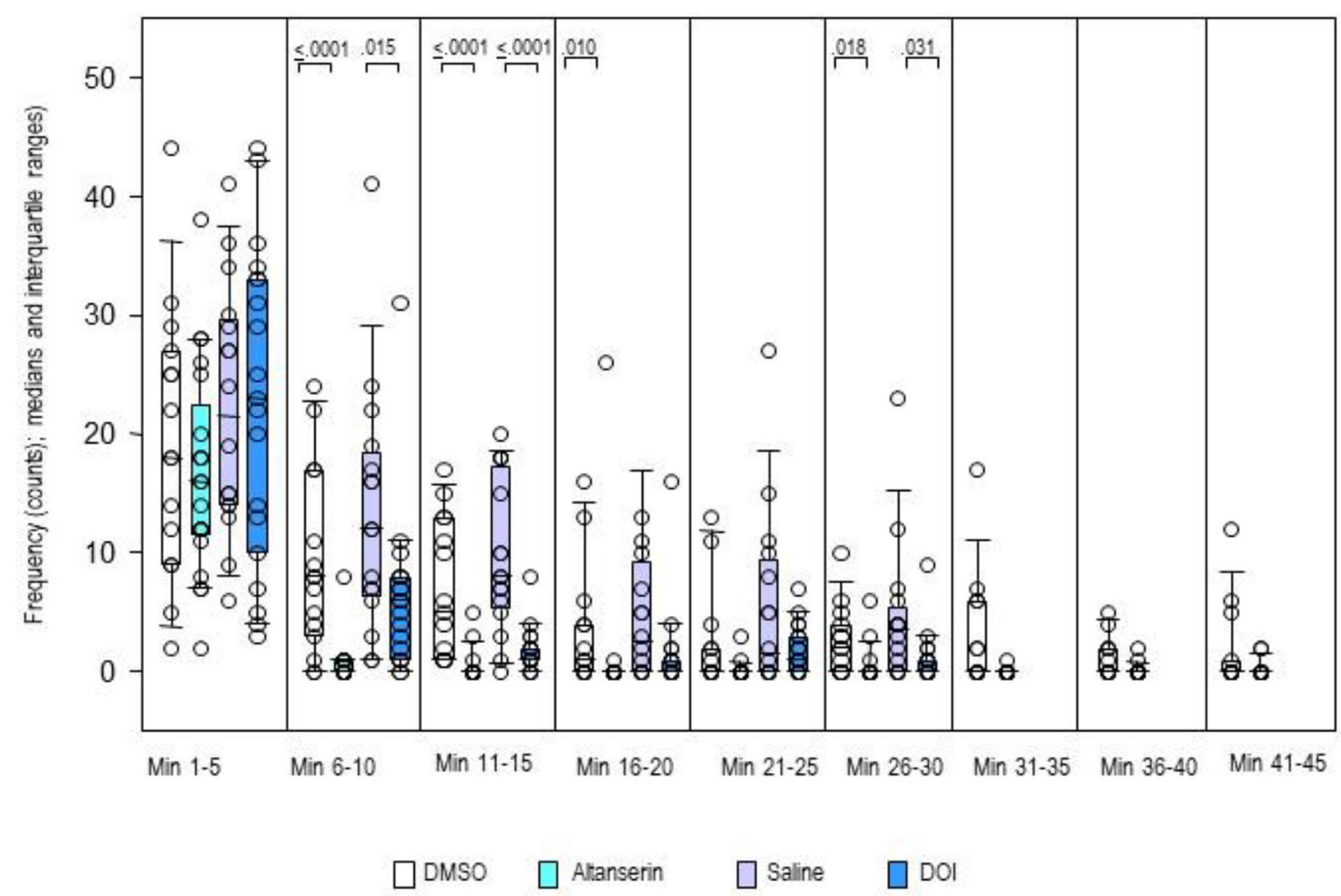

FIGURE 9 | Rearing. Duration (s) and frequency (counts) after $10 \mathrm{mg} / \mathrm{kg}$ of altanserin (turquoise), $0.5 \mathrm{mg} / \mathrm{kg}$ of 2,5-dimethoxy-4-iodoamphetamine (DOI; blue), and the respective vehicles [dimethyl sulfoxide (DMSO), white; saline, light purple]. The figure shows box and whisker plots of median rearing durations (A) and frequencies (B) in the individual 5-min bins. The 25th/75th percentiles are given in the boxes, while the 5th/95th percentiles are represented by the whiskers. The circles represent the individual animals. Groups (altanserin vs. DMSO; DOI vs. saline) were compared with the independent Mann-Whitney U-test (two-tailed, $\alpha=0.05)$. Significant $p$-values are given. 
A

Head and shoulder motility

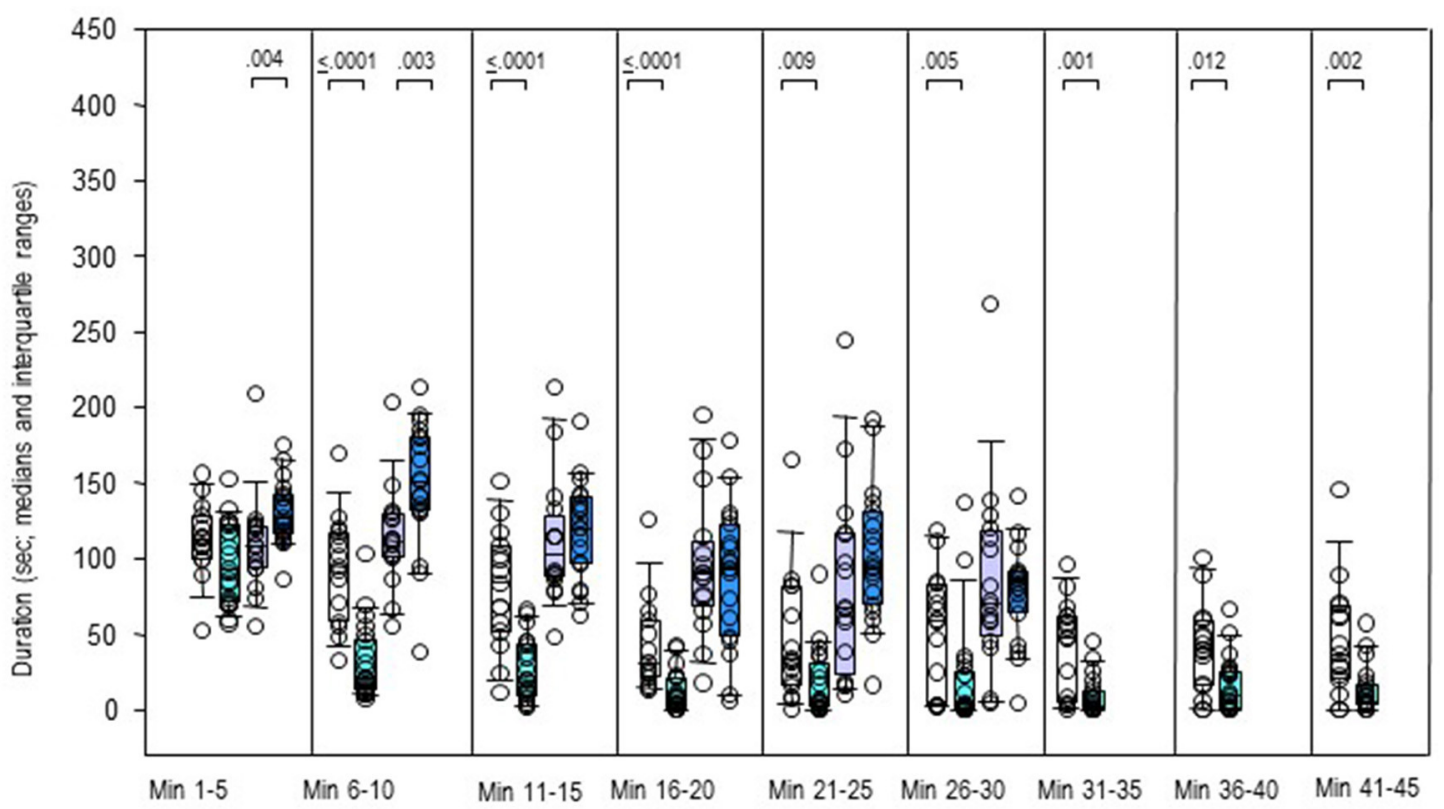

B

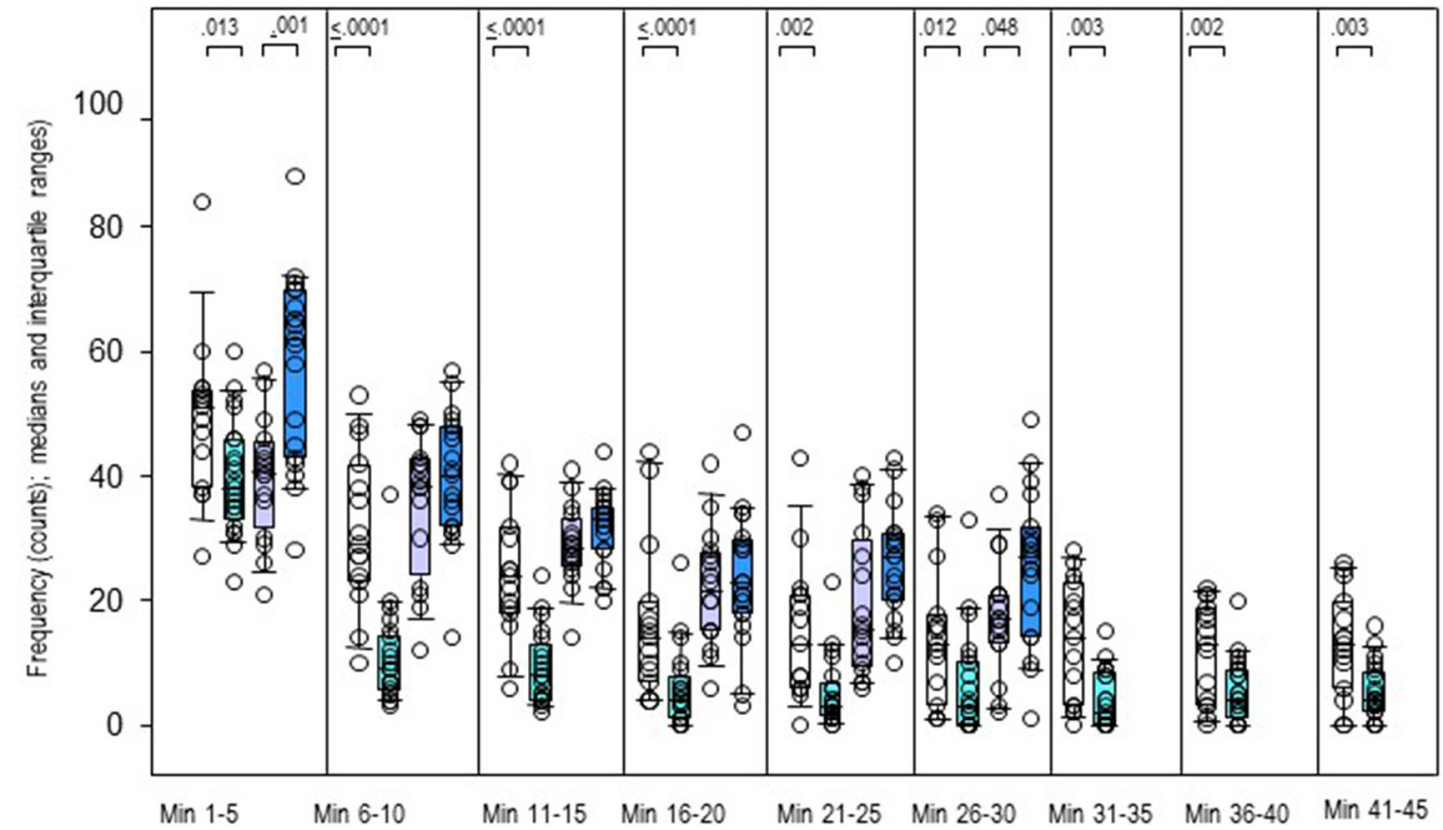

$\square$ DMSO $\square$ Avianserin $\square$ Saline $\square$ DOI

FIGURE 10 | Head-shoulder motility. Duration (s) and frequency (counts) after $10 \mathrm{mg} / \mathrm{kg}$ of altanserin (turquoise), $0.5 \mathrm{mg} / \mathrm{kg}$ of 2,5-dimethoxy-4-iodoamphetamine (DOI; blue), and the respective vehicles [dimethyl sulfoxide (DMSO), white; saline, light purple]. The figure shows box and whisker plots of median durations (A) and frequencies (B) in the individual 5-min bins. The 25th/75th percentiles are given in the boxes, while the 5th/95th percentiles are represented by the whiskers. The circles represent the individual animals. Groups (altanserin vs. DMSO; DOI vs. saline) were compared with the independent Mann-Whitney U-test (two-tailed, $\alpha=$ 0.05). Significant $p$-values are given. 
input from the $\mathrm{CP}$ to the neocortex together with the increased availability of GABA in the latter region incurred a net reduction of GLUergic input to the THAL, resulting in normal DA levels, as observed in the present investigation. After both SAL and DOI, network analyses yielded strong positive connections between FC and MC as well as THAL and FC and a strong negative connection between SN/VTA and MC. Interestingly, however, after DOI, the positive connections between NAC and PC, SN/VTA and FC, and SN/VTA and MC turned negative, while a negative connection between THAL and PC and two positive connections between NAC and both FC and MC were introduced. This implies an involvement of mesolimbocortical as well corticocortical projections in the regulation of synaptic DA. Future in vivo imaging studies with different doses of DOI are required in order to further elucidate this matter.

The HIPP receives DAergic neurons originating in the VTA (Nazari-Serenjeh et al., 2011), which-along with its most prominent projection area, the NAC-displayed no changes of $\mathrm{D}_{2 / 3} \mathrm{R}$ binding under the present experimental conditions. Previously, DOI was found to elevate GLU levels in the VTA (Pehek et al., 2006). Given the known facilitatory effect of 5$\mathrm{HT}_{2 \mathrm{~A}}$ Rs also on GABAergic neurotransmission (Jiang et al., 2009), it may be that the elevation of GABAergic inhibition exerted by DOI in the VTA, in analogy to its actions in the SN, outweighed GLUergic excitation, leading to a reduction of DA levels in the hippocampal target regions of ventral tegmental projections, which is reflected by the observed elevation of radioligand binding to the $\mathrm{D}_{2 / 3} \mathrm{R}$ in the vHIPP. The contribution of SN/VTA is underlined by the strong positive connection between this region and vHIPP obtained in network analysis. Interestingly, however, DOI also introduced strong positive connections between THAL and dHIPP, THAL and vHIPP, and $\mathrm{PC}$ and dHIPP as well as a strong negative connection between dHIPP and vHIPP. The emergence of limbic connections after DOI relative to SAL reflects the relevance of the 5-HTergic system for limbic function. Also here, further investigations are required in order to gain more insight into the 5-HT-triggered regulatory mechanisms of limbic DA.

After DMSO, strong positive connections were found between NAC and THAL and FC and PC, which turned negative after ALT. Conversely, a strong negative connection between NAC and PC turned positive after ALT. Besides, ALT introduced strong positive connections between NAC and vHIPP, SN/VTA and MC, THAL and PC, THAL and AHIPP, MC and PC, MC and $\mathrm{dHIPP}$, and $\mathrm{MC}$ and vHIPP as well as strong negative connections between NAC and dHIPP and PC and vHIPP.

Since both GABA efflux (Jiang et al., 2009) and GLU efflux (Meller et al., 2002) are stimulated by $5-\mathrm{HT}_{2 \mathrm{~A}} \mathrm{R}$ action, application of a $5-\mathrm{HT}_{2 \mathrm{~A}} \mathrm{R}$ antagonist likely reduces the inhibitory GABAergic as well as the excitatory GLUergic effects of 5-HT. Hence, the increases of DA efflux in the CP after application of ALT reported by Dewey et al. (1995) may have been due to a decrease of GABAergic inhibition relative to the reduction of GLUergic excitation, leading to a net increase of available DA. Presumably, in the present study, a decrease of GABAergic inhibition induced by the dose of $10 \mathrm{mg} / \mathrm{kg}$ of ALT was either too short-termed or so low that it could be compensated by the reduction of GLUergic excitation, incurring no alteration of $\mathrm{D}_{2 / 3} \mathrm{R}$ binding in the $\mathrm{CP}$ indicative of altered synaptic DA levels. This presumption is underlined by the lack of connection between the SN/VTA and CP in network analyses.

It may be assumed that, in contrast to DOI, the $5-\mathrm{HT}_{2 \mathrm{~A}} \mathrm{R}$ antagonist also did not decrease the GABAergic input from the THAL to the neocortex relative to the GLUergic input, resulting in unaltered DA levels in the cortical regions. This is supported by the lack of connection between THAL and FC in network analysis.

For the vHIPP, it can be hypothesized that, in a reversal of the actions exerted by DOI, a reduction of GLUergic excitation outweighed the simultaneous decrease of GABAergic inhibition, also-ultimately-resulting in a decline of DA levels (and the observed increase of $\mathrm{D}_{2 / 3} \mathrm{R}$ binding) in the vHIPP. Also here, the contribution of SN/VTA is underlined by the strengthened positive connection between this region and vHIPP obtained in network analysis.

Also, ALT introduced strong connections between regions of the mesolimbothalamocortical system including positive associations between NAC and PC, NAC and vHIPP, SN/VTA and AHIPP, THAL and AHIPP, and THAL and PC and negative associations between NAC and THAL, NAC and dHIPP, and $\mathrm{MC}$ and vHIPP. Thereby, however, the $5-\mathrm{HT}_{2 \mathrm{~A}} \mathrm{R}$ agonist in contrast to the $5-\mathrm{HT}_{2 \mathrm{~A}} \mathrm{R}$ antagonist induced strong positive connections between $\mathrm{CP}$ and PC, SN/VTA and CP, SN/VTA and dHIPP, THAL and FC, and PC and AHIPP and a strong negative connection between NAC and PC, and dHIPP and vHIPP. Moreover, it strengthened the positive connections between the THAL and both parts of the HIPP and the negative connection between SN/VTA and FC. This implies that DOI exerted more varied and stronger effects in comparison to ALT, which is also reflected by the fact that DOI affected $\mathrm{D}_{2 / 3} \mathrm{R}$ binding also in the striatal and neocortical regions.

\section{Behavior}

The $5-\mathrm{HT}_{2 \mathrm{~A}} \mathrm{R}$ agonist as well as antagonist decreased parameters of motor activity (overall activity and ambulation duration) and active exploratory behavior (rearing duration and frequency). Thereby, after DOI, reductions of motor activity were confined to min 1-20 (overall activity) and min 1-5 (ambulation duration). However, while DOI increased duration and frequency of explorative head-shoulder movements, but did not affect passive immobility (sitting duration), ALT decreased explorative headshoulder motility and increased passive immobility. In sum, the reduction of motor activity was more pronounced after ALT, while the reductions of active (vertical) exploration were comparable after ALT and DOI.

The finding of diminished ambulatory behavior after ALT confirms the results obtained in a previous study (Kennett, 1992). Likewise, results obtained after DOI corroborate precedent findings of reduced ambulatory (Hillegaart et al., 1996; KrebsThomson et al., 1998; Zaniewska et al., 2009) and rearing behaviors (Hillegaart et al., 1996; Krebs-Thomson et al., 1998; Hawkins et al., 2002) upon systemic pretreatment with DOI. They are not consistent, however, with the findings on ambulation by Hawkins et al. (2002), who observed no effect on 
motor activity after i.c.v. administration of $0.02-0.2 \mathrm{mg}$ as well as s.c. administration of $0.1-1 \mathrm{mg} / \mathrm{kg}$. A likely reason for this discrepancy is that Hawkins et al. (2002) performed their open field test 10 min after a tail-pinch stress test (Hawkins et al., 2002), which may have influenced the animals' activity.

Joint investigations of motor/exploratory behaviors and $\mathrm{D}_{2 / 3} \mathrm{R}$ imaging have shown that, in mature rats, decreases of regional $\mathrm{D}_{2 / 3} \mathrm{R}$ binding (indicative of elevated $\mathrm{DA}$ ) were related to decreases of motor/exploratory activity (e.g., Nikolaus et al., 2016, 2018, 2019). Also, in the present study, parameters of motor activity and vertical exploratory behavior were reduced by $5-\mathrm{HT}_{2 \mathrm{~A}} \mathrm{R}$ agonistic as well as antagonistic treatment, with decreases, however, more pronounced and extended over a longer period after ALT compared with DOI. This may reflect the rise of extracellular DA, which was reported for either compound in in vivo microdialysis studies shortly post-injection (Dewey et al., 1995; Gobert and Millan, 1999). In context with our previous findings, the reduction of motor/explorative behaviors is in striking contrast to the reductions of $\mathrm{D}_{2 / 3} \mathrm{R}$ binding observed in vHIPP after ALT and in CP, FC, MC, and vHIPP after DOI, which, rather, indicate decreased DA levels in these regions. This infers that the regional elevations of synaptic DA indicated by the behavioral findings could not be visualized in the chosen time windows for in vivo imaging (90-150 min post-challenge for ALT and 75-135 min post-challenge for DOI). After ALT and DOI, DA levels peaked from 40 to $60 \mathrm{~min}$ (Dewey et al., 1995) and 20 to 60 min post-challenge (Gobert and Millan, 1999), respectively, with a steady reduction thereafter. Apparently, in the time between radioligand application and the achievement of binding equilibrium, the decline of DA levels incurred a decrease of competition for $\mathrm{D}_{2 / 3} \mathrm{R}$ binding sites, which, in conjunction with the higher affinity of $\left[{ }^{123} \mathrm{I}\right] \mathrm{IBZM}$ $\left(K_{D}=0.3 \mathrm{nM}\right.$; Verhoeff et al., 1991) relative to the endogenous ligand $\left(\mathrm{K}_{\mathrm{D}}=1.2 \mathrm{nM}\right.$, de Paulis et al., 1988) resulted in the observed reductions of $\mathrm{D}_{2 / 3} \mathrm{R}$ binding. Future in vivo imaging studies after various concentrations of ALT and DOI and with radioligand injection at various times post-challenge are required to further elucidate the time dependency of the effects, which are exerted by ALT and DOI on regional $\mathrm{D}_{2 / 3} \mathrm{R}$ binding (and DA levels).

\section{Appraisal}

For one, also the vehicle DMSO might have induced pharmacological effects. Unpublished results have shown that neostriatal $\mathrm{D}_{2 / 3} \mathrm{R}$ binding after DMSO was elevated relative to SAL. Also in the present study, tentative comparisons of $\mathrm{D}_{2 / 3} \mathrm{R}$ BPs have yielded increased receptor binding in NAC, $\mathrm{CP}, \mathrm{FC}$, and MC of DMSO-treated relative to SAL-treated rats. Moreover, there is evidence that DMSO decreased motor/exploratory behaviors relative to SAL. In the present study, such differences were observed for overall activity (min 1-30), ambulation duration (min 1-10), sitting duration (min $1-5$ and 26-30), sitting frequency (min 1-5), rearing duration (min 11-15), duration of head-shoulder motility (min 16-20), and frequency of head-shoulder motility (min 6-10). Hence, it cannot be excluded that the effects of ALT added upon pharmacological effects of DMSO. For this reason, behaviors as well as regional BPs were only compared between 5-HTergic challenges and the respective vehicle but not between ALT and DOI.

Second, in the present in vivo studies, the maximum VOI diameters were either in the range of or beyond the spatial resolution of the employed imaging tool. It must be considered, however, that in those portions of VOIs, whose diameters are smaller than the FWHM, the exact quantification of $\mathrm{D}_{2 / 3} \mathrm{R}$ binding may be hampered by partial volume effects leading to underestimations of radioligand accumulation. A further source of error may be spillover from regions with high radioligand accumulation such as the extraorbital Harderian glands to the adjacent VOIs of the FC, CP, and NAC, or from the CP to NAC, THAL, and dHIPP, causing overestimations of radioligand binding. However, since this pertains to SPECT measurements both in baseline and after challenge, the exactitude of (semi)quantitative values in either condition, but not the comparability of data between baseline and challenge, may have been biased.

Third, in vivo imaging findings may have been flawed by the employment of the NMDAR antagonist ketamine as anesthetic. Since ketamine has previously been shown to enhance DA release and reduce $\mathrm{D}_{2 / 3} \mathrm{R}$ binding in rats (e.g., Tsukada et al., 2000), it cannot be dismissed that also in the present study increased DA levels due to ketamine usage reduced the amounts of visible regional $\mathrm{D}_{2 / 3} \mathrm{R}$ binding after both $\mathrm{ALT}$ and DOI. However, effects on neostriatal and/or ventrostriatal DA are exerted by practically all known anesthetics, including pentobarbital, propofol, halothane, chloral hydrate, and isoflurane (for review, see Müller et al., 2011). Since ketamine was employed in all our previous in vivo imaging studies, we, therefore, decided to use it also in the present investigation. As this possible pitfall concerns the outcome of SPECT measurements after 5-HTergic challenges as well as after treatment with the respective vehicles, the obtained BPs remain comparable between conditions. The publications of Gudelsky et al. (1994) and Gobert and Millan (1999) do not give information on the state of the animals during microdialytic sampling. However, in the experiment of Ichikawa and Meltzer (1995), who observed no changes of striatal DA concentrations upon infusion of DOI, dialysates were drawn, while the rats were freely moving. Hence, it must be taken into account that anesthesia as such may have contributed to the differences between studies.

Fourth, in this and other investigations (e.g., Nikolaus et al., 2016, 2017, 2018, 2019), effects of DAergic, GABAergic, glutamatergic, and 5-HTergic challenges on regional $D_{2} R$ binding and motor/exploratory behaviors have merely been assessed in male rats. The main reason for not using female animals is their estrous cycle, which is characterized by four phases with distinct fluctuations of estrogen and progesterone concentrations (Butcher et al., 1974). Thus, if the hormonal state of the female rodent is to be accounted for, the number of subjects per experiment multiplies, since four times more females than males have to be examined. Nevertheless, there is not only evidence of sex differences in incidence and onset of stress-related and other psychiatric disorders (for review, see ter Horst et al., 2012) but also of an interaction 
between ovarian hormone and monoamine function (Janowsky et al., 1971). As a consequence, future studies should also be conducted on female rats in order to duly assess the impact of the hormonal state on $\mathrm{D}_{2 / 3} \mathrm{R}$ binding under a given pharmacological challenge.

\section{CONCLUSION}

Taken together, the $5-\mathrm{HT}_{2 \mathrm{~A}} \mathrm{R}$ agonistic DOI increased $\mathrm{D}_{2 / 3} \mathrm{R}$ binding (and presumably decreased DA) in the $\mathrm{CP}$ as well as in the limbic and neocortical target regions (vHIPP, FC, and $\mathrm{MC}$ ) of ascending 5-HTergic as well as DAergic projections. After application of the $5-\mathrm{HT}_{2 \mathrm{~A}} \mathrm{R}$ antagonistic ALT, the increase of $\mathrm{D}_{2 / 3} \mathrm{R}$ binding (and the decrease of $\mathrm{DA}$ ) was confined to vHIPP. Both ALT and DOI decreased parameters of motor activity and active (vertical) exploration. However, while DOI increased explorative head-shoulder motility, ALT decreased explorative head-shoulder motility and increased passive immobility. The reductions of motor/exploratory activities contrast the regional reductions of $\mathrm{D}_{2 / 3} \mathrm{R}$ binding, as they indicate elevated DA levels at the time of behavioral measurements. It may be concluded that ALT and DOI modulated DA in the individual regions of the nigrostriatal and mesolimbocortical pathways differentially and in a time-dependent fashion.

\section{REFERENCES}

Alex, K. D., and Pehek, E. A. (2007). Pharmacologic mechanisms of serotonergic regulation of dopamine neurotransmission. Pharmacol. Ther. 113, 296-320. doi: 10.1016/j.pharmthera.2006.08.004

Alex, K. D., Yavanian, G. J., McFarlane, H. G., Pluto, C. P., and Pehek, E. A. (2005). Modulation of dopamine release by striatal 5-HT2C receptors. Synapse 55, 242-251. doi: 10.1002/syn.20109

Appel, N. M., Mitchell, W. M., Garlick, R. K., Glennon, R. A., Teitler, M., and De Souza, R. B. (1990). Autoradiographic characterization of (+-)-1-(2,5dimethoxy-4-[125I] iodophenyl)-2-aminopropane ([125I]DOI) binding to 5HT2 and 5-HT1c receptors in rat brain. J. Pharmacol. Exp. Ther. 255, 843-857.

Arias-Carrión, O., and Poppel, E. (2007). Dopamine, learning, and reward-seeking behavior. Acta Neurobiol. Exp. 67, 481-488.

Belin, M. F., Aguera, M., Tappaz, M., McRae-Degueurce, A., Bobillier, P., and Pujol, J. F. (1979). GABA-accumulating neurons in the nucleus raphe dorsalis and periaqueductal gray in the rat: a biochemical and radioautographic study. Brain Res. 170, 279-297. doi: 10.1016/0006-8993(79)90107-0

Bortolozzi, A., Díaz-Mataix, L., Scorza, M. C., Celada, P., and Artigas, F. (2005). The activation of 5-HT receptors in prefrontal cortex enhances dopaminergic activity. J. Neurochem. 95, 1597-1607. doi: 10.1111/j.1471-4159.2005.03485.x

Bouthenet, M. L., Martres, M. P., Sales, N., and Schwartz, J. C. (1987). A detailed mapping of dopamine D-2 receptors in rat central nervous system by autoradiography with [125I]iodosulpride. Neuroscience 20, 117-155. doi: 10.1016/0306-4522(87)90008-X

Burke, M. V., Nocjar, C., Sonneborn, A. J., McCreary, A. C., and Pehek, E. A. (2014). Striatal serotonin $2 \mathrm{C}$ receptors decrease nigrostriatal dopamine release by increasing GABA-A receptor tone in the substantia nigra. J. Neurochem. 131, 432-443. doi: 10.1111/jnc.12842

Butcher, R. L., Collins, W. E., and Fugo, N. W. (1974). Plasma concentration of LH, FSH, prolactin, progesterone and estradiol-17beta throughout the 4-day estrous cycle of the rat. Endocrinology 94, 1704-1708. doi: 10.1210/endo-94-6-1704

Camps, M., Cortés, R., Gueye, B., Probst, A., and Palacios, J. M. (1989). Dopamine receptors in human brain: autoradiographic distribution of D2 sites. Neuroscience 28, 275-290. doi: 10.1016/0306-4522(89)90179-6

\section{DATA AVAILABILITY STATEMENT}

The raw data supporting the conclusions of this article will be made available by the authors, without undue reservation.

\section{ETHICS STATEMENT}

The animal study was reviewed and approved by Landesamt für Natur, Umwelt und Verbraucherschutz Nordrhein-Westfalen, Recklinghausen, Germany.

\section{AUTHOR CONTRIBUTIONS}

SN, JPH, GA, and H-WM: experimental design. SN, H-JW, $\mathrm{YM}$, and $\mathrm{CD}$ : performance of imaging and behavioral studies. SN and MB: evaluation and statistical analysis. SN, JPH, and $\mathrm{H}-\mathrm{WM}$ : interpretation of findings. SN, H-JW, MB, CA, EM, $\mathrm{YM}, \mathrm{HH}, \mathrm{CD}, \mathrm{JPH}$, and $\mathrm{H}-\mathrm{WM}$ : writing and editing of the manuscript. All authors contributed to the article and approved the submitted version.

\section{FUNDING}

JPH was supported by Deutsche Forschungsgemeinschaft (Grant: DFG HU 306/27-3).

Canal, C. E., Booth, R. G., and Morgan, D. (2013). Support for 5HT2C receptor functional selectivity in vivo utilizing structurally diverse, selective 5-HT2C receptor ligands and the 2,5-dimethoxy-4-iodoamphetamine elicited head-twitch response model. Neuropharmacology 70, 112-121. doi: 10.1016/j.neuropharm.2013.01.007

Carpenter, M. B., Carleton, S. C., Keller, J. T., and Conte, P. (1981). Connections of the subthalamic nucleus in the monkey. Brain Res. 224, 1-29. doi: 10.1016/0006-8993(81)91113-6

de Paulis, T., Janowsky, A., Kessler, R. M., Clanton, J. A., and Smith, H. E. (1988). (S)-N-[(1-ethyl-2-pyrrolidinyl)methyl]-5-[125I]iodo-2-methoxybenzamide hydrochloride, a new selective radioligand for dopamine D-2 receptors. J. Med. Chem. 31, 2027-2033. doi: 10.1021/jm00118a031

Dewey, S. L., Smith, G. S., Logan, J., Alexoff, D., Ding, Y. S., King, P., et al. (1995). Serotonergic modulation of striatal dopamine measured with positron emission tomography (PET) and in vivo microdialysis. J. Neurosci. 15, 821-829. doi: 10.1523/JNEUROSCI.15-01-00821.1995

Doherty, M. D., and Pickel, V. M. (2000). Ultrastructural localization of the serotonin 2A receptor in dopaminergic neurons in the ventral tegmental area. Brain Res. 864, 176-185. doi: 10.1016/S0006-8993(00) 02062-X

Eid, L., and Parent, M. (2016). Chemical anatomy of pallidal afferents in primates. Brain Struct. Funct. 221, 4291-4317. doi: 10.1007/s00429-016-1216-y

Fischer, A. G., and Ullsperger, M. (2017). An update on the role of serotonin and its interplay with dopamine for reward. Front. Hum. Neurosci. 11:484. doi: 10.3389/fnhum.2017.00484

Friedman, J., Hastie, T., and Tibshirani, R. (2008). Sparse inverse covariance estimation with the graphical lasso. Biostatistics 9, 432-441. doi: 10.1093/biostatistics/kxm045

Gobert, A., and Millan, J. M. (1999). Serotonin (5-HT)2A receptor activation enhances dialysate levels of dopamine and noradrenaline, but not 5-HT, in the frontal cortex of freely-moving rats. Neuropharmacology 38, 315-317. doi: 10.1016/S0028-3908(98)00188-9

Groves, P. M. (1983). A theory of the functional organization of the neostriatum and the neostriatal control of voluntary movement. Brain Res. 5, 109-132. doi: 10.1016/0165-0173(83)90011-5 
Gudelsky, G. A., Yamamoto, B. K., and Nash, J. F. (1994). Potentiation of 3,4methylenedi-oxymethamphetamine-induced dopamine release and serotonin neurotoxicity by 5-HT2 receptor agonists. Eur. J. Pharmacol. 264, 325-330. doi: 10.1016/0014-2999(94)90669-6

Haase, A., Frahm, J., Matthaei, D., Hänicke, W., and Merboldt, K. D. (1986). FLASH imaging. Rapid NMR imaging using low flip-angle pulses. J. Magn. Reson. 67, 258-266. doi: 10.1016/0022-2364(86)90433-6

Hawkins, M. F., Uzelac, S. M., Baumeister, A. A., Hearn, J. K., Broussard, J. I., and Guillot, T. S. (2002). Behavioral responses to stress following central and peripheral injection of the 5-HT(2) agonist DOI. Pharmacol. Biochem. Behav. 73, 537-544. doi: 10.1016/S0091-3057(02)00822-5

Hillegaart, V., Estival, A., and Ahlenius, S. (1996). Evidence for specific involvement of 5-HT1A and 5-HT2A/C receptors in the expression of patterns of spontaneous motor activity of the rat. Eur. J. Pharmacol. 295, 155-161. doi: 10.1016/0014-2999(95)00666-4

Hume, S. P., Gunn, R. N., and Jones, T. (1998). Pharmacological constraints associated with positron emission tomographic scanning of small laboratory animals. Eur. J. Nucl. Med. 25, 173-176. doi: 10.1007/s002590050211

Ichikawa, J., and Meltzer, H. Y. (1995). DOI, a 5-HT2A/2C receptor agonist, potentiates amphetamine-induced dopamine release in rat striatum. Brain Res. 698, 204-208. doi: 10.1016/0006-8993(95)00865-N

Ichise, M., Meyer, J. H., and Yonekura, Y. (2001). An introduction to PET and SPECT neuroreceptor quantification models. J. Nucl, Med. 42, 755-763.

Janowsky, D. S., Fann, W. E., and Davis, J. M. (1971). Monoamines and ovarian hormone-linked sexual and emotional changes: a review. Arch. Sex Behav. 1, 205-218. doi: 10.1007/BF01541683

Jiang, X., Xing, G., Yang, C., Verma, A., Zhang, L., and Li, H. (2009). Stress impairs 5-HT2A receptor-mediated serotonergic facilitation of GABA release in juvenile rat basolateral amygdala. Neuropsychopharmacology 34, 410-423. doi: $10.1038 / \mathrm{npp} .2008 .71$

Jongen, C., de Bruin, K., Beekman, F., and Booij, J. (2008). SPECT imaging of D2 dopamine receptors and endogenous dopamine release in mice. Eur. J. Nucl. Med. Mol. Imaging 35, 1692-1698. doi: 10.1007/s00259-008-0795-0

Kaneko, T., Akiyama, H., Nagatsu, I., and Mizuno, N. (1990). Immunohistochemical demonstration of glutaminase in catecholaminergic and serotoninergic neurons of rat brain. Brain Res. 15, 151-154. doi: 10.1016/0006-8993(90)90535-J

Kawashima, T. (2018). The role of the serotonergic system in motor control. Neurosci. Res. 129, 32-39. doi: 10.1016/j.neures.2017.07.005

Kazakov, V. N., Kravtsov, P. Y., Krakhotkina, E. D., and Maisky, V. A. (1993). Sources of cortical, hypothalamic and spinal serotonergic projections: topical organization within the nucleus raphe dorsalis. Neuroscience 56, 157-164. doi: 10.1016/0306-4522(93)90570-6

Kennett, G. A. (1992). 5-HT1C receptor antagonists have anxiolytic-like actions in the rat social interaction model. Psychopharmacology 107, 379-384. doi: $10.1007 / \mathrm{BF} 02245165$

Kievit, J., and Kuypers, H. G. (1975). Basal forebrain and hypothalamic connection to frontal and parietal cortex in the Rhesus monkey. Science 187, 660-662. doi: $10.1126 /$ science. 1114317

Köhler, C., and Steinbusch, H. (1982). Identification of serotonin and non-serotonin-containing neurons of the mid-brain raphe projecting to the entorhinal area and the hippocampal formation. A combined immunohistochemical and fluorescent retrograde tracing study in the rat brain. Neuroscience 7, 951-975. doi: 10.1016/0306-4522(82)90054-9

Krebs-Thomson, K., Lehmann-Masten, V., Naiem, S., Paulus, M. P., and Geyer, M. A. (1998). Modulation of phencyclidine-induced changes in locomotor activity and patterns in rats by serotonin. Eur. J. Pharmacol. 343, 135-143. doi: 10.1016/S0014-2999(97)01557-4

Kristiansen, H., Elfving, B., Plenge, P., Pinborg, L. H., Gillings, N., and Knudsen, G. M. (2005). Binding characteristics of the 5-HT2A receptor antagonists altanserin and MDL 100907. Synapse 58, 249-257. doi: 10.1002/syn.20205

Langer, S. Z. (1974). Presynaptic regulation of catecholamine release. Biochem. Pharmacol. 23, 1793-1800. doi: 10.1016/0006-2952(74)90187-7

Larsen, P. J., Hay-Schmidt, A., Vrang, N., and Mikkelsen, J. D. (1996). Origin of projections from the midbrain raphe nuclei to the hypothalamic paraventricular nucleus in the rat: a combined retrograde and anterograde tracing study. Neuroscience 70, 963-988 doi: 10.1016/0306-4522(95) 00415-7
Laruelle, M. (2000). Imaging synaptic neurotransmission with in vivo binding competition techniques: a critical review. J. Cereb. Blood Flow Metab. 20, 423-451. doi: 10.1097/00004647-200003000-00001

Leysen, J. (1989). "Use of 5-HT receptor agonists and antagonists for the characterization of their respective recptor sites," in Drugs as Tools in Neurotransmitter Research. Neuromethods, eds A. B. Boulton, G. B. Baker, and A. V. Jurio (Clifton, NJ: The Human Press), 299-341.

Li, Y. Q., Takada, M., Shinonaga, Y., and Mizuno, N. (1993). Direct projections from the midbrain periaqueductal gray and the dorsal raphe nucleus to the trigeminal sensory complex in the rat. Neuroscience 54, 431-443. doi: 10.1016/0306-4522(93)90264-G

López-Giménez, J. F., Vilar,ó, M. T., Palacios, J. M., and Mengod, G. (2001). Mapping of 5-HT2A receptors and their mRNA in monkey brain: [3H]MDL100,907 autoradiography and in situ hybridization studies. J. Comp. Neurol. 429, 571-589. doi: 10.1002/1096-9861(20010122)429:4<571::AIDCNE5 > 3.0.CO;2-X

Lucas, G., and Spampinato, U. (2000). Role of striatal serotonin2A and serotonin2C receptor subtypes in the control of in vivo dopamine outflow in the rat striatum. J. Neurochem. 74, 693-701. doi: 10.1046/j.1471-4159.2000.740693.x

Ma, Q. P., and Han, J. S. (1992). Neurochemical and morphological evidence of an antinociceptive neural pathway from nucleus raphe dorsalis to nucleus accumbens in the rabbit. Brain Res. Bull. 28, 931-936. doi: 10.1016/0361-9230(92)90215-J

Manaker, S., and Fogarty, P. F. (1995). Raphespinal and reticulospinal neurons project to the dorsal vagal complex in the rat. Exp. Brain Res. 106, 79-92. doi: 10.1007/BF00241358

Mann, E. O., Kohl, M. M., and Paulsen, O. (2009). Distinct roles of GABA(A) and GABA(B) receptors in balancing and terminating persistent cortical activity. J. Neurosci. 29, 7513-7518. doi: 10.1523/JNEUROSCI.6162-08.2009

Meller, R., Harrison, P. J., Elliott, J. M., and Sharp, T. (2002). In vitro evidence that 5-hydroxytryptamine increases efflux of glial glutamate via 5-HT(2A) receptor activation. J. Neurosci. Res. 67, 399-405. doi: 10.1002/jnr.10126

Moore, R. Y., Halaris, A. E., and Jones,. B. E. (1978). Serotonin neurons of the midbrain raphe: ascending projections. J. Comp. Neurol. 180, 417-438. doi: $10.1002 /$ cne. 901800302

Morelli, M., Mennini, T., Cagnotto, A., Toffano, G., and Di Chiara, G. (1990). Quantitative autoradiographical analysis of the age-related modulation of central dopamine D1 and D2 receptors. Neuroscience 36, 403-410. doi: 10.1016/0306-4522(90)90435-7

Müller, C. P., Pum, M. E., Amato, D., Schüttler, J., Huston, J. P., and Silva, M. A., $\mathrm{T}$ (2011). The in vivo neurochemistry of the brain during general anesthesia. $J$. Neurochem. 119, 419-446. doi: 10.1111/j.1471-4159.2011.07445.x

Müller, C. P., Thönnessen, H., Jochamm, G., Barrosm, M., Tomaz, C., Carey, R. J., et al. (2004). Cocaine-induced 'active immobility' and its modulation by the serotonin1A receptor. Behav. Pharmacol. 15, 481-493. doi: 10.1097/00008877-200411000-00004

Nazari-Serenjeh, F., Rezayof, A., and Zarrindast, M. R. (2011). Functional correlation between GABAergic and dopaminergic systems of dorsal hippocampus and ventral tegmental area in passive avoidance learning in rats. Neuroscience 24, 104-114. doi: 10.1016/j.neuroscience.2011.08.073

Neto, F. L., Ferreira-Gomes, J., and Castro-Lopes, J. M. (2006). Distribution of GABA receptors in the thalamus and their involvement in nociception. Adv. Pharmacol. 54, 29-51. doi: 10.1016/S1054-3589(06)54002-5

Ng, N. K., Lee, H. S., and Wong, P. T. (1999). Regulation of striatal dopamine release through 5-HT1 and 5-HT2 receptors. Neurosci. Res. 55, 600-607. doi: 10.1002/(SICI)1097-4547(19990301)55:5<600::AID-JNR7>3.0.CO;2-\#

Nikolaus, S., Antke, C., and Müller, H. W. (2009a). In vivo imaging of synaptic function in the central nervous system. I. Movement disorders and dementia. Behav. Brain Res. 204, 1-31. doi: 10.1016/j.bbr.2009. 06.008

Nikolaus, S., Antke, C., and Müller, H. W. (2009b). In vivo imaging of synaptic function in the central nervous system. II. Mental and affective disorders. Behav. Brain Res. 204, 32-66. doi: 10.1016/j.bbr.2009.06.009

Nikolaus, S., Beu, M., De Souza Silva, A. M., Huston, J. P., Antke, C., Müller, $H$. W., et al. (2017). GABAergic control of neostriatal dopamine $\mathrm{D}_{2}$ receptor binding and behaviors in the rat. Pharmacol. Biochem. Behav. 153, 76-87. doi: $10.1016 /$ j.pbb.2016.12.012 
Nikolaus, S., Beu, M., De Souza Silva, A. M., Huston, J. P., Hautzel, H., Mattern, C., et al. (2016). Relationship between L-DOPA-induced reduction in motor and exploratory activity and striatal dopamine $\mathrm{D}_{2}$ receptor binding in the rat. Front. Behav. Neurosci. 9:352. doi: 10.3389/fnbeh.2015.00352

Nikolaus, S., Wittsack, J., Beu, M., Antke, C., De Souza Silva, M. A., Wickrath, F., et al. (2018). GABAergic control of nigrostriatal and mesolimbic dopamine in the rat brain. Front. Behav. Neurosci. 12:38. doi: 10.3389/fnbeh.2018.00038

Nikolaus, S., Wittsack, J., Wickrath, F., Müller-Lutz, A., Hautzel, H., Beu, M., et al. (2019). Differential effects of D-cycloserine and amantadine on motor behavior and $\mathrm{D}_{2 / 3}$ receptor binding in the nigrostriatal and mesolimbic system of the adult rat. Sci. Rep. 9:16128. doi: 10.1038/s41598-019-52185-7

Oades, R. D., and Halliday, G. M. (1987). Ventral tegmental (A10) system: neurobiology. 1. Anatomy and connectivity. Brain Res. 434, 117-165. doi: 10.1016/0165-0173(87)90011-7

Ochi, J., and Shimizu, K. (1978). Occurrence of dopamine-containing neurons in the midbrain raphe nuclei of the rat. Neurosci. Lett. 8, 317-320. doi: 10.1016/0304-3940(78)90142-8

Paxinos, G., and Watson, C. (2014). The Rat Brain in Stereotaxix Coordinates. 7th ed. Amsterdam: Academic Press, Elesevier.

Pehek, E. A., Nocjar, C., Roth, B. L., Byrd, T. A., and Mabrouk, O. S. (2006). Evidence for the preferential involvement of 5-HT2A serotonin receptors in stress- and drug-induced dopamine release in the rat medial prefrontal cortex. Neuropsychopharmacology 31, 265-277. doi: 10.1038/sj.npp.1300819

Ribeiro-do-Valle, L. E. (1997). Serotonergic neurons in the caudal raphe nuclei discharge in association with activity of masticatory muscles. Braz. J. Med. Biol. Res. 30, 79-83. doi: 10.1590/S0100-879X1997000100013

Salt, T. E., Eaton, S. A., and Turner, J. P. (1996). Characterization of the metabotropic glutamate receptors (mGluRs) which modulate GABAmediated inhibition in the ventrobasal thalamus. Neurochem. Int. 29, 317-322. doi: 10.1016/0197-0186(95)00146-8

Schiffer, W. K., Mirrione, M. M., Biegon, A., Alexoff, D. L., Patel, V., and Dewey, S. L. (2006). Serial microPET measures of the metabolic reaction to a microdialysis probe implant. J. Neurosci. Methods. 155, 272-284. doi: 10.1016/j.jneumeth.2006.01.027

Schramm, N., Wirrwar, A., Sonnenberg, F., and Halling, H. (2000). Compact high resolution detector for small animal SPECT. IEEE Trans. Nucl. Sci. 47, 1163-1166. doi: 10.1109/23.856564

Seeman, P., and Grigoriadis, D. (1987). Dopamine receptors in brain and periphery. Neurochem. Int. 10, 1-25. doi: 10.1016/0197-0186(87)90167-7

Sherman, S. M. (2014). The function of metabotropic glutamate receptors in thalamus and cortex. Neuroscientist. 20, 136-149. doi: $10.1177 / 1073858413478490$

Steinbusch, H. W., van der Kooy, D., Verhofstad, A. A., and Pellegrino, A. (1980). Serotonergic and non-serotonergic projections from the nucleus raphe dorsalis to the caudate-putamen complex in the rat, studied by a combined immunofluorescence and fluorescent retrograde axonal labeling technique. Neurosci. Lett. 19, 137-142. doi: 10.1016/0304-3940(80)90184-6

Steininger, T. L., Wainer, B. H., Blakely, R. D., and Rye, D. B. (1997). Serotonergic dorsal raphe nucleus projections to the cholinergic and noncholinergic neurons of the pedunculopontine tegmental region: a light and electron microscopic anterograde tracing and immunohistochemical study. J. Comp. Neurol. 382, 302-322. doi: 10.1002/(SICI)1096-9861(19970609)382:3<302::AID-CNE2>3.0. $\mathrm{CO} ; 2-7$

Stratford, T. R., and Wirtshafter, D. (1990). Ascending dopaminergic projections from the dorsal raphe nucleus in the rat. Brain Res. 511, 173-176. doi: 10.1016/0006-8993(90)90239-8
Tan, P. Z., Baldwin, R. M., Van Dyck, C. H., Al-Tikriti, M., Roth, B., Khan, N., et al. (1999). Characterization of radioactive metabolites of 5-HT2A receptor PET ligand [18F] altanserin in human and rodent. Nucl. Med. Biol. 26, 601-608. doi: 10.1016/S0969-8051(99)00022-0

ter Horst, J. P., de Kloet, E. R., Schächinger, H., and Oitzl, M. S. (2012). Relevance of stress and female sex hormones for emotion and cognition. Cell. Mol. Neurobiol. 32, 725-735. doi: 10.1007/s10571-011-9774-2

Thompson, A. M., Moore, K. R., and Thompson, G. C. (1995). Distribution and origin of serotoninergic afferents to guinea pig cochlear nucleus. J. Comp. Neurol. 351, 104-116. doi: 10.1002/cne.903510110

Torigoe, Y., Blanks, R. H., and Precht, W. J. (1986). Anatomical studies on the nucleus reticularis tegmenti pontis in the pigmented rat. I. Cytoarchitecture, topography, and cerebral cortical afferents. J. Comp. Neurol. 243, 71-87. doi: $10.1002 /$ cne. 902430107

Tsukada, H., Harada, N., Nishiyama, S., Ohba, H., Sato, K., Fukumoto, D., et al. (2000). Ketamine decreased striatal $\left[{ }^{11} \mathrm{C}\right]$ raclopride binding with no alteration in static dopamine concentrations in the striatal extracellular fluid in the monkey brain: Multi-parametric PET studies combined with microdialysis analysis. Synapse 37, 95-103. doi: 10.1002/1098-2396(200008)37:2<95::AID-SYN3>3.0.CO;2-H

Verhoeff, N. P. L. G., Bobeldijk, M., Feenstra, M. P. G., Boer, G. J., Maas, M. A. W., Erdtsieck-Ernste, E., et al. (1991). In vitro and in vivo $\mathrm{D}_{2}$-dopamine receptor binding with $\left(\left({ }^{123} \mathrm{I}\right) \mathrm{IBZM}\right)$ in rat and human brain. Int. J. Rad. Appl. Instrum. B. 18, 837-846. doi: 10.1016/0883-2897(91)90091-X

Villar, M. J., Vitale, M. L., Hökfelt, T., and Verhofstad, A. A. (1988). Dorsal raphe serotoninergic branching neurons projecting both to the lateral geniculate body and superior colliculus: a combined retrograde tracing-immunohistochemical study in the rat. J. Comp. Neurol. 277, 126-140. doi: 10.1002/cne.902770109

Wirtshafter, D., Stratford, T. R., and Asin, K. E. (1987). Evidence that serotonergic projections to the substantia nigra in the rat arise in the dorsal, but not the median, raphe nucleus. Neurosci. Lett. 77, 261-266. doi: 10.1016/0304-3940(87)90509-X

Yan, Q., Reith, M. E., and Yan, S. (2000). Enhanced accumbal dopamine release following $5-\mathrm{HT}(2 \mathrm{~A})$ receptor stimulation in rats pretreated with intermittent cocaine. Brain Res. 863, 254-258. doi: 10.1016/S0006-8993(00)02080-1

Zaniewska, M., McCreary, A. C., and Filip, M. (2009). Interactions of serotonin (5-HT)2 receptor-targeting ligands and nicotine: locomotor activity studies in rats. Synapse 63, 653-661. doi: 10.1002/syn.20645

Conflict of Interest: The authors declare that the research was conducted in the absence of any commercial or financial relationships that could be construed as a potential conflict of interest.

Publisher's Note: All claims expressed in this article are solely those of the authors and do not necessarily represent those of their affiliated organizations, or those of the publisher, the editors and the reviewers. Any product that may be evaluated in this article, or claim that may be made by its manufacturer, is not guaranteed or endorsed by the publisher.

Copyright (c) 2021 Nikolaus, Wittsack, Antke, Beu, Hautzel, Decheva, Mamlins, Mori, Huston, Antoch and Müller. This is an open-access article distributed under the terms of the Creative Commons Attribution License (CC BY). The use, distribution or reproduction in other forums is permitted, provided the original author(s) and the copyright owner(s) are credited and that the original publication in this journal is cited, in accordance with accepted academic practice. No use, distribution or reproduction is permitted which does not comply with these terms. 